\title{
SBID
}

Banco Interamericano de Desarrollo

\section{Servicios intensivos en conocimiento en la industria del petróleo en Colombia}

\author{
Instituciones para el \\ Desarrollo \\ División de \\ Competitividad \\ e Innovación \\ DOCUMENTO PARA \\ DISCUSIÓN № \\ IDB-DP-417
}

Juan Miguel Gallego Hernán Jaramillo Andrés Patiño 


\section{Servicios intensivos en conocimiento en la industria del petróleo en Colombia}

Juan Miguel Gallego

Hernán Jaramillo

Andrés Patiño

Facultad de Economía,

Universidad del Rosario 
http://www.iadb.org

Copyright (c) 2015 Banco Interamericano de Desarrollo. Esta obra se encuentra sujeta a una licencia Creative Commons IGO 3.0 Reconocimiento-NoComercial-SinObrasDerivadas (CC-IGO 3.0 BY-NC-ND) (http://

creativecommons.org/licenses/by-nc-nd/3.0/igo/legalcode) y puede ser reproducida para cualquier uso nocomercial otorgando el reconocimiento respectivo al BID. No se permiten obras derivadas.

Cualquier disputa relacionada con el uso de las obras del BID que no pueda resolverse amistosamente se someterá a arbitraje de conformidad con las reglas de la CNUDMI (UNCITRAL). El uso del nombre del BID para cualquier fin distinto al reconocimiento respectivo y el uso del logotipo del BID, no están autorizados por esta licencia CC-IGO y requieren de un acuerdo de licencia adicional.

Note que el enlace URL incluye términos y condiciones adicionales de esta licencia.

Las opiniones expresadas en esta publicación son de los autores y no necesariamente reflejan el punto de vista del Banco Interamericano de Desarrollo, de su Directorio Ejecutivo ni de los países que representa.

\section{(c) (i) $(9)$ \\ BY NC ND}

Contacto: Gustavo Crespi, gcrespi@iadb.org. 


\begin{abstract}
Resumen $^{*}$
En la última década, la industria de hidrocarburos en Colombia experimentó una expansión de la producción de petróleo, con impactos significativos tanto en los indicadores macroeconómicos del país como en la dinámica del sector y, más importante para este trabajo, en la dinámica de la industria de bienes y servicios derivados de la actividad de producción de este recurso natural. La industria de bienes y servicios derivados del petróleo se caracteriza por enfrentar retos tecnológicos que demandan innovaciones en el descubrimiento y desarrollo de nuevos yacimientos en diferentes países, lo cual permite el crecimiento de empresas locales prestadoras de servicios capaces de adaptar tecnologías de frontera y de generar innovaciones locales. Para el caso colombiano, en 2014 se puede observar la presencia de firmas nuevas locales en los diferentes servicios de la cadena de valor del sector de bienes y servicios del petróleo y la consolidación de empresas locales con experiencia en el sector que compiten con sus contrapartes extranjeras, las cuales son empresas de carácter global que mantienen presencia en diferentes regiones del mundo con experiencia reconocida. Se observa una especialización mayor por parte de las empresas jóvenes de origen nacional en pocos mercados de la cadena comparado con empresas nacionales de larga experiencia en el sector y con firmas multinacionales que participan en muchos servicios a lo largo de toda la cadena de valor. Finalmente, este documento presenta los retos que plantea el sector en términos de regulación y políticas institucionales para incentivar la actividad de producción de hidrocarburos en todas sus etapas en un contexto de precios internacionales desfavorables para la materia prima, y señala los potenciales impactos sobre el desarrollo de capacidades locales medidos, por ejemplo, en disminuciones de la oferta de ingenieros del sector y de la empleabilidad de los mismos.
\end{abstract}

Códigos JEL: O30, Q35

Palabras clave: innovación, capacidades locales, petróleo, cadena de valor

\footnotetext{
* Este trabajo fue financiado por el Banco Interamericano de Desarrollo bajo el proyecto titulado "Knowledge intensive business services in the petrouleum industry and palm oil industry in Colombia" en el marco del proyecto general "Knowledge intensive service in Natural Resources based industries: a new path", contrato RG-K1360. Los autores agradecen los comentarios de Gustavo Crespi, Jorge Katz, Jocelyn Olivari y todos los miembros de los otros estudios enmarcados en el mismo proyecto.
} 


\section{Introducción}

En la última década, la industria de hidrocarburos en Colombia experimentó una expansión de la producción de petróleo, con impactos significativos tanto en los ingresos fiscales derivados de la explotación de dicho recurso como en el desarrollo de empresas que participan en la operación y explotación de los yacimientos y en empresas prestadoras de servicios petroleros. El petróleo ha contribuido con cerca del $5 \%$ del producto interno bruto (PIB) del país y da cuenta de cerca del $30 \%$ de los ingresos fiscales del Estado. Aunque no se lo considera un país petrolero, dado que su producción en 2014 representó, en promedio, el 8,5\% de la producción de petróleo de Estados Unidos (principal productor después de Arabia Saudita), sí se encuentra entre los 20 países con mayor producción y se clasifica como un país con petróleo. Esta dinámica positiva de la industria petrolera colombiana estuvo relacionada con la evolución creciente de los precios internacionales del crudo, los cuales disminuyeron significativamente en los últimos meses. ${ }^{1}$

Dadas la dinámica observada y las recientes presiones sobre el desarrollo de la industria como consecuencia de la caída de los precios internacionales, cabe preguntarse si existen posibilidades de desarrollo de empresas prestadoras de servicios, no solo de capital extranjero sino también empresas locales. En particular, es importante entender si se puede mantener una dinámica estable de empresas prestadoras de servicios con capacidad de adaptación tecnológica y de desarrollo innovador que permitan mejorar la productividad en el sector y que estén menos sujetas al ciclo económico del crudo. En este sentido, el objetivo general de este trabajo es explicar la evolución reciente de esta industria, la entrada de empresas prestadoras de servicios petroleros de carácter multinacional, la estabilización de antiguas empresas nacionales y el surgimiento de nuevas prestadoras locales de servicios. Este estudio se enmarca en el contexto de un sector petrolero altamente innovador, característica que está dada por la importancia del sector mismo, por los retos tecnológicos para extraer el crudo y por los cambios tecnológicos debido a las particularidades de los bloques y campos que están en el subsuelo.

Desde sus orígenes, la industria de hidrocarburos en Colombia, como ocurre en toda la industria a nivel mundial, ha contado con la presencia de empresas proveedoras de servicios, en especial aquellas intensivas en conocimiento y alta tecnología. La existencia de estas empresas de servicios es el resultado de una organización industrial desintegrada verticalmente entre empresas operadoras de yacimientos de petróleo y empresas prestadoras de servicios asociados a la explotación del recurso natural. Por otro lado, la explotación de este recurso no renovable, que tiende rápidamente al agotamiento de las reservas existentes y obliga a una búsqueda continua de nuevos pozos, genera necesidades en la provisión de servicios de alto valor tecnológico y de innovaciones para el desarrollo de las actividades derivadas del petróleo. Asimismo, es una industria altamente globalizada donde interactúan grandes empresas multinacionales, tanto operadoras como prestadoras de servicios, en busca de nuevas reservas a nivel mundial con retos tecnológicos que demandan nuevas innovaciones y generan posibilidades de desarrollo de

\footnotetext{
${ }^{1}$ Dado que Colombia no ha sido un productor histórico de petróleo, se puede pensar que existe poca experiencia en el establecimiento de instituciones regulatorias que permitan un desempeño adecuado del sector y el surgimiento de líneas de servicios. Sin embargo, Ecopetrol, la empresa estatal de explotación de petróleo, ha jugado un papel fundamental en el buen desarrollo de la industria y los arreglos institucionales recientes, como la creación de la Agencia Nacional de Hidrocarburos y agencias de regulación ambiental, que permiten prever arreglos institucionales adecuados que estimulan la explotación y el desarrollo de la industria.
} 
empresas locales prestadoras de servicios capaces de adaptar tecnológicas de frontera y de generar innovaciones locales.

Por otro lado, al igual que en otros países, la industria colombiana de petróleo cuenta con la tradición de una empresa estatal petrolera que promueve, dentro de sus objetivos de explotación del recurso, la adquisición de capacidades de investigación y desarrollo. Como esta capacitación está determinada por una decisión estatal y no está sujeta al ciclo económico del sector, juega un papel importante en el desarrollo de capacidades de conocimiento y tecnológicas. Esto permite que el sector cuente con recursos humanos y tecnológicos, pilares fundamentales para el desarrollo local de prestadores de servicios intensivos en conocimiento.

En particular, en este estudio se busca describir si la dinámica de este sector permite ilustrar una oportunidad tecnológica importante para el desarrollo de la industria local de alto nivel tecnológico de empresas prestadoras de servicios. La metodología empleada para alcanzar dicho objetivo es describir y estudiar la evolución de la cadena de valor de hidrocarburos desde la perspectiva de exploración bottom up (de abajo hacia arriba). Este enfoque permite entender la organización industrial de las empresas de servicios que han surgido en función del desarrollo del sector de petróleo en Colombia, y permite, además, analizar las distintas etapas en las que se conformaron y entraron al mercado las nuevas firmas en las diferentes fases de la cadena de valor: exploración, evaluación y desarrollo, y desarrollo y producción. Asimismo, este estudio explora la existencia de servicios relacionados con la explotación del recurso más allá de la cadena de valor: los que se relacionan con la transformación de productos del petróleo mediante procesos de refinación y la elaboración de productos derivados de la petroquímica.

Dentro de esta cadena de valor agregado se encuentran particularidades, desarrollos desiguales en los servicios que se prestan y acumulación de capacidades tecnológicas. A la vez, el tamaño y la concentración de las firmas, los orígenes del capital, el desarrollo de diversos servicios, la innovación y la investigación presentan un complejo de realidades diferenciadas. En el sector se tiende en general hacia la separación de funciones: el activo del operador son las reservas y el activo de las empresas de servicios es la tecnología. A pesar de esta tendencia se ha podido observar una relativa integración vertical en la empresa estatal de petróleo, Ecopetrol, que realiza actividades de investigación e innovación a través del Instituto Colombiano del Petróleo (ICP) y lleva a cabo algunas de las funciones de las tres grandes áreas en que se agrupan las fases de la cadena de valor. Históricamente, Ecopetrol ha jugado un papel muy importante porque ha logrado una buena caracterización de las fases de desarrollo tecnológico y de innovación por las que ha atravesado desde sus comienzos y ha reconocido el valor del aprendizaje tecnológico y esto a su vez se ha transferido a todo el sector petrolero.

Además de esta primera sección introductoria, este estudio se organiza de la siguiente forma. En la sección 2 se busca ilustrar la importancia del sector de hidrocarburos para el país. La primera parte explica el estado actual de la industria del petróleo en el país, concentrándose en describir la evolución del precio del petróleo, de las reservas probadas y de la actividad de exploración. En la segunda parte de la sección 2 se muestra como se relaciona el sector petrolero con la economía del país. En la sección 3 se describe la cadena de valor del sector de hidrocarburos, para lo cual se identifican las empresas y se tipifican por su capital y años de experiencia. Además, se analiza si existe alguna tipología que pueda explicar la oferta de bienes y 
servicios por parte de las empresas a lo largo de la cadena de valor. En la sección 4 se describe el caso de Ecopetrol como dinamizador de la industria del petróleo en Colombia. La sección 5 presenta a manera de discusión los retos tecnológicos y su relación con la regulación que enfrenta actualmente la industria del petróleo en Colombia. La sección 6 presenta los comentarios finales.

\section{El sector de hidrocarburos: una industria dinámica con impactos significativos en la economía de Colombia}

Un tema reciente ilustrativo de la importancia del sector del petróleo en la economía colombiana lo constituye la reciente crisis de precios del petróleo a nivel mundial. La caída de los precios del petróleo ha tenido un impacto importante en el ajuste de las finanzas públicas: en el presupuesto general de la nación para el año 2015 el valor del petróleo se había proyectado a US\$90 el barril, y la caída del precio ha significado un aumento en el déficit fiscal. Esto ha implicado una desmejora significativa en los ingresos regionales derivados del ingreso de regalías. De igual forma se revirtió la revaluación cambiaria que se daba en el contexto de precios altos del crudo y se acentuó la devaluación del peso colombiano frente al dólar.

En el contexto anterior de precios internacionales altos, la industria había mostrado un crecimiento importante en cuanto a exploración y aumentos de producción. Sin embargo, no se habían realizado esfuerzos suficientes para aumentar de manera importante las reservas de petróleo que permitieran "pasar la crisis" con una situación de política petrolera más favorable, ni se había constituido un fondo de estabilización de largo plazo para la época de crisis. Por otra parte, la situación colombiana presenta un panorama aún más complejo para sobreponerse a períodos de crisis como el actual, dadas sus características. Por un lado, los nuevos pozos que se están descubriendo son cada vez menos de crudos livianos y de yacimientos convencionales; por otro lado, los costos de exploración son cada vez mayores: crudos pesados, producción de pozos en recuperación, offshore y exploración en yacimientos no convencionales. Estas características encarecen la extracción de crudo en un momento en el que los precios son bajos.

En síntesis, el petróleo tiene estrecha relación con una amplia gama de factores. En primer lugar, el petróleo está muy vinculado al ámbito de desarrollo y crecimiento, así como a la política cambiaria, el déficit fiscal y cambios en la balanza comercial, dado que pueden incrementarse las exportaciones - por el tipo de cambio- y restringirse las importaciones. Además, el petróleo se relaciona con diversas áreas de política -económica y fiscal; comercio exterior; industrial, agrícola y de servicios; exploración petrolera; inversión extranjera; social y de ingresos regionales-, todas las cuales confluyen en la necesidad de ajustarse de manera consistente y coherente para poder avanzar en una senda de crecimiento económico y social. En el aspecto sectorial y de productividad a nivel de empresas se observa que los desarrollos recientes de la industria del petróleo ayudan a impulsar la construcción de capacidades tecnológicas y de aprendizaje entre las empresas, ya que un porcentaje importante de las empresas en esta industria pertenecen a multinacionales con amplia experiencia en otros países, lo cual facilita la transferencia de conocimiento hacia las empresas locales. 


\subsection{Evolución reciente del sector petrolero}

La actividad petrolera ha venido teniendo un desarrollo y crecimiento importante en el país, como lo muestran los distintos indicadores que reflejan su estado. Este crecimiento se ha beneficiado especialmente del estímulo de los precios internacionales, como se muestra en el gráfico 1. La dinámica de los precios se debe a varios factores. Respecto al alza de precios, se han identificado tres motivos fundamentales: a) el crecimiento de China y el aumento de la demanda en India, que trajeron como consecuencia el llamado boom de las materias primas; b) el crecimiento de la productividad de sectores de servicios asociados a recursos naturales, y c) el desarrollo de las tecnologías de información. Por otra parte, la reciente caída de los precios se ha justificado por las siguientes razones: a) un menor crecimiento de los países asiáticos, en particular China; b) señales de estancamiento en los países europeos, en especial Alemania; c) el cambio ocurrido en Estados Unidos, que pasó de ser dependiente de petróleo importado a autoabastecedor del mismo; d) razones de política y conflicto internacional, y e) desarrollos tecnológicos y de innovación.

\section{Gráfico 1. Precio anual del petróleo (en US\$ por barril)}

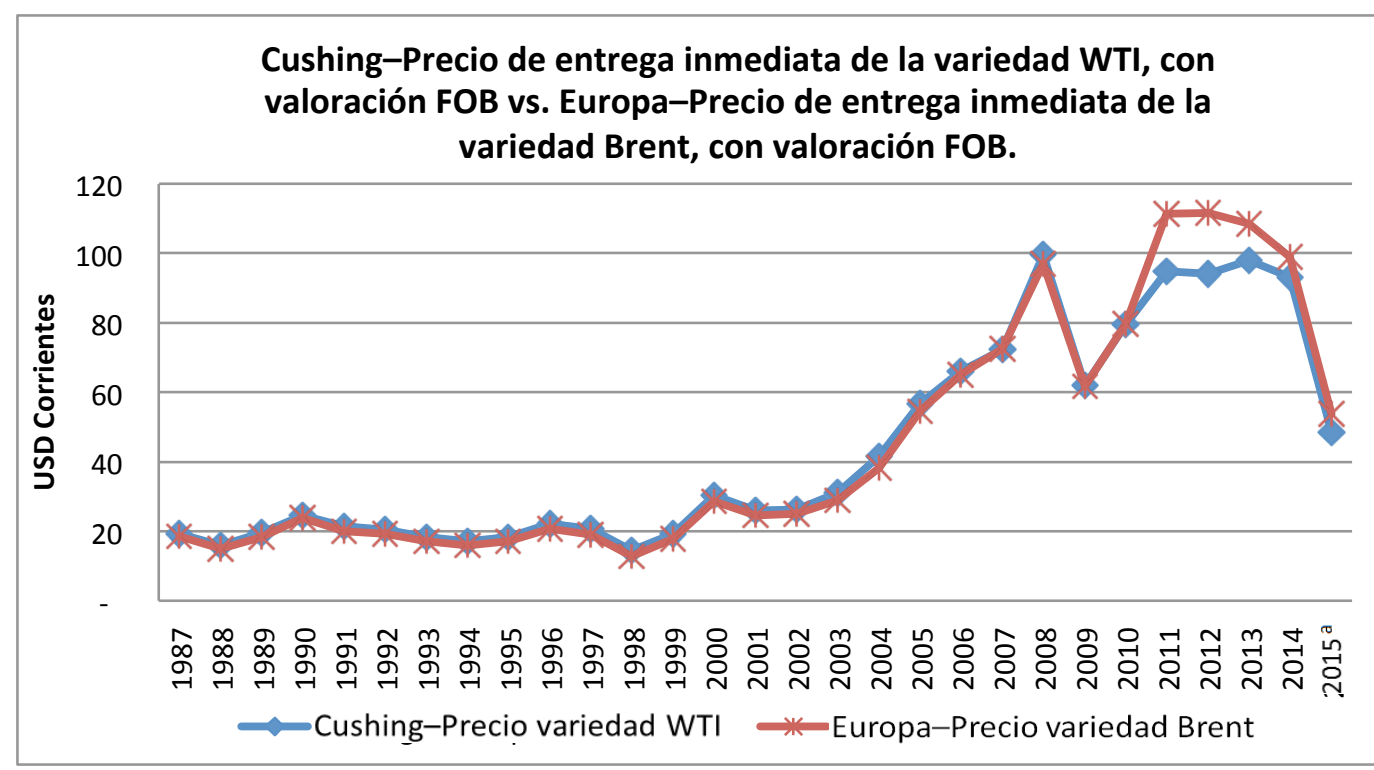

Fuentes: Tomado del IEP-ACP. US Inflation Calculator. Banco de la República - Balanza de pagos.

${ }^{a}$ Precios de WTI y Brent al 27 de marzo de 2015. Inflación promedio de Estados Unidos en febrero de 2015.

En este contexto de cambio "abrupto" es importante mantener los niveles de inversión en exploración, perforación y desarrollo de campos nuevos y de recuperación. El gráfico 2 muestra que las reservas probadas están disminuyendo (las barras en azul) y que existen nuevos descubrimientos, pero estos últimos han ocurrido con mayor frecuencia en pozos de tamaño pequeño (véase el gráfico 3). Por otro lado, se observa una disminución en la perforación de pozos, lo cual reduce las posibilidades de hallar nuevas reservas. En particular, para el caso colombiano y como se muestra en el gráfico 2 y el cuadro 1, la situación de reservas es muy precaria dado que la relación reservas sobre producción daría para 6,5 años. La disminución de la presión sobre los indicadores básicos del sector dependerá de la política pública, del papel de la mayor empresa estatal, Ecopetrol, en cuanto a no suspender radicalmente sus inversiones planeadas y del comportamiento posiblemente diferente que tengan las compañías extranjeras. 


\section{Gráfico 2}

Colombia: Incorporación de reservas anuales (Mbbl) y número de pozos perforados

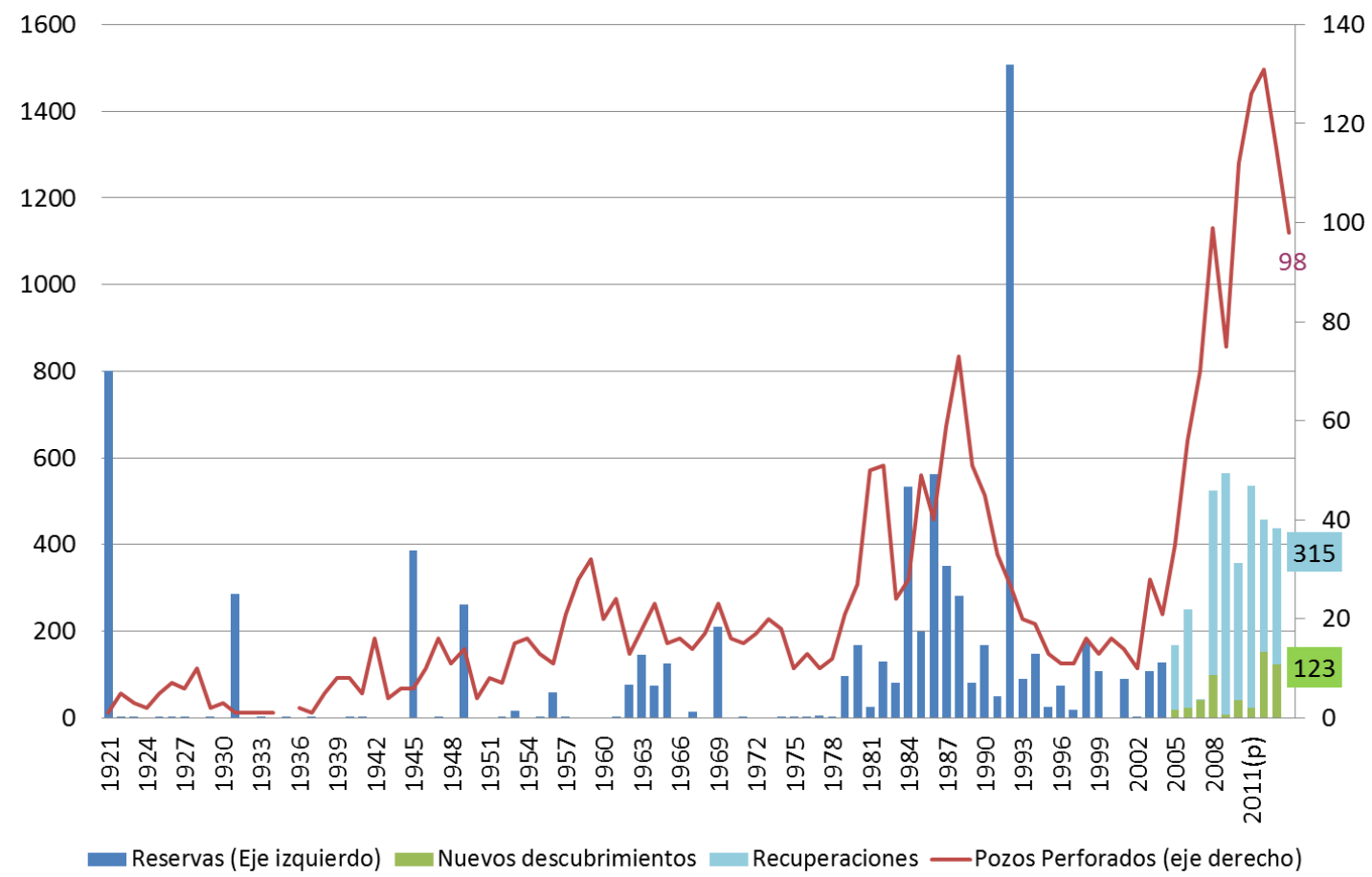

Fuente: Agencia Nacional de Hidrocarburos, tomado de Echeverry (2015).

$\mathrm{Mbbl}=$ millones de barriles

Cuadro 1. Reservas, nuevos descubrimientos y revaluaciones de crudo (en millones de barriles [Mbbl])

\begin{tabular}{|l|c|c|c|c|c|}
\hline Año & $\begin{array}{l}\text { Incorporación por } \\
\text { revaluaciones }\end{array}$ & $\begin{array}{l}\text { Nuevos } \\
\text { descubrimientos }\end{array}$ & $\begin{array}{l}\text { Total incorporado } \\
\text { anual }\end{array}$ & $\begin{array}{l}\text { Producción } \\
\text { anual }\end{array}$ & $\begin{array}{l}\text { Reservas } \\
\text { probadas }\end{array}$ \\
\hline 2008 & 425 & 98,5 & 524 & 215 & 1.668 \\
\hline 2009 & 558 & 6,8 & 565 & 245 & 1.988 \\
\hline 2010 & 317 & 40,0 & 357 & 287 & 2.058 \\
\hline 2011 & 512 & 22,6 & 535 & 334 & 2.259 \\
\hline 2012 & 312 & 152,0 & 464 & 346 & 2.377 \\
\hline
\end{tabular}

Fuentes: Tomado del IEP-ACP. ANH (informe de gestión 2013).

Una interpretación más completa del gráfico 3 muestra que los hallazgos recientes han ocurrido principalmente en campos pequeños, con lo cual se deben resolver varios dilemas por circunstancias propias, de niveles al límite de la explotación de yacimientos convencionales y de recuperación primaria, y quizás sea necesario un movimiento hacia yacimientos de recobro mayor, yacimientos no convencionales y a la exploración de posibilidades de yacimientos en plataformas marinas. Todo ello requiere mayores inversiones y adopción de nuevas tecnologías e innovaciones de aplicación al sector petrolero colombiano. En este momento el sector está enfrentando retos de política que permitan estabilizar la dinámica reciente de la industria y de este modo mantener el desempeño adecuado de las empresas prestadoras de servicios. 
Gráfico 3

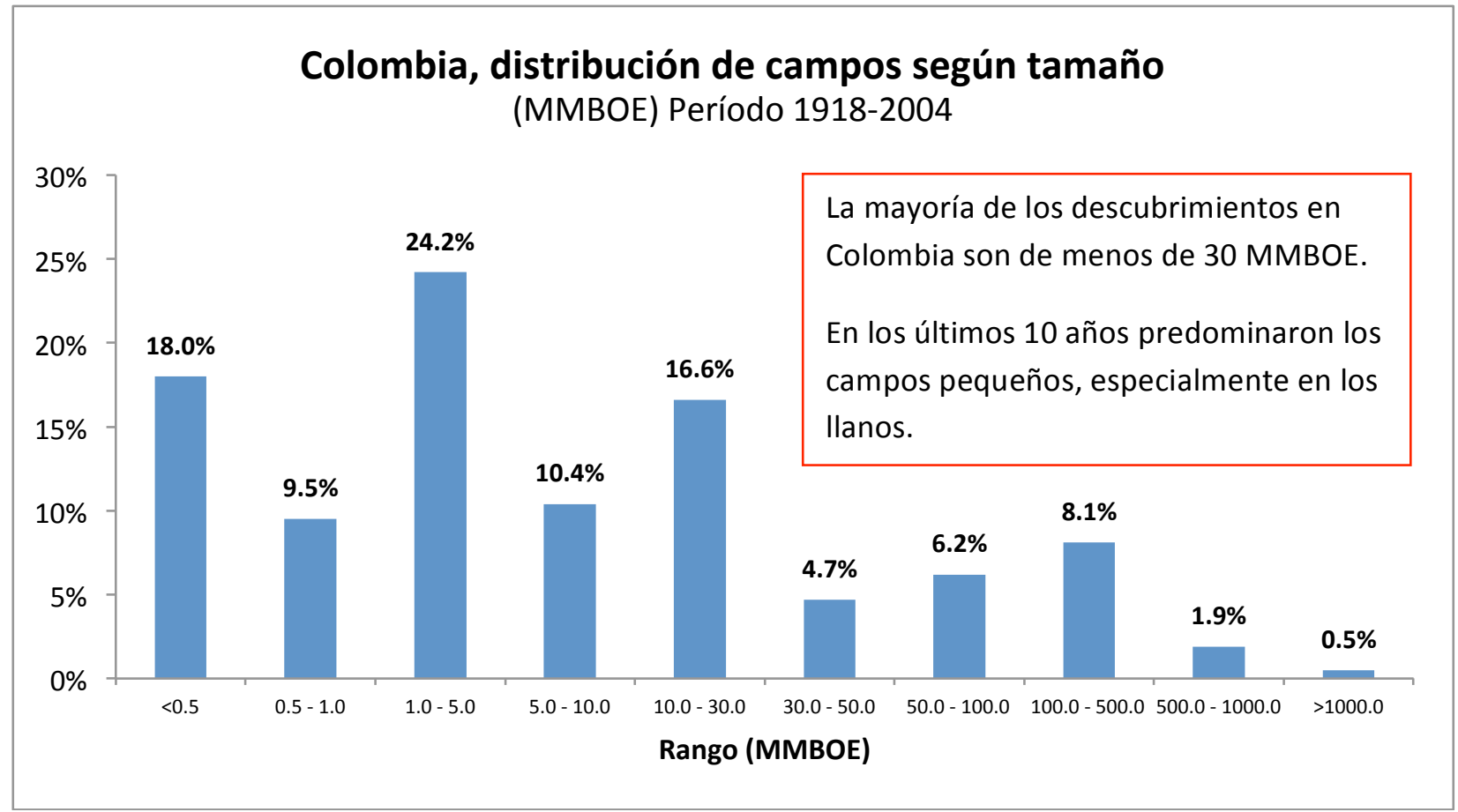

Fuente: Echeverry (2015).

MMBOE $=$ Millones de barriles de petróleo equivalente

Con respecto a la situación actual de disminución dramática de los precios internacionales, se han tomado dos decisiones de política pública: una relativa a la empresa estatal, Ecopetrol, y otra en política tributaria. Por una parte, la Junta Directiva de la empresa estatal colombiana, frente a los cambios de situación en los precios internacionales, decidió reducir el Plan de Inversiones para 2015 en un $25,8 \%$, lo que significa que las inversiones de la empresa estatal serán de US\$7.860 millones frente a las actuales inversiones de US\$10.595 millones. De las inversiones para 2015 , se ha establecido que US $\$ 4.145$ millones se destinarán a producción; US $\$ 1.800$ millones serán invertidos en refinación y petroquímica; US\$503 millones en exploración, y US\$40 millones en hidrocarburos asociados a yacimientos no convencionales, entre otros. Es preocupante esta disminución tan drástica y se espera que permanezca solo este primer año de la crisis de precios y que la inversión se corrija en años posteriores, dada la relación entre reservas remanentes de crudo y volumen y años de reservas tan bajas de Colombia, como se indica en el gráfico 4. Por otra parte, y con el objetivo de estimular la exploración offshore, el gobierno colombiano ha establecido estímulos para las empresas extranjeras que decidan o que ya tengan asignados bloques en este tipo de área. ${ }^{2}$

\footnotetext{
${ }^{2}$ En la Ley de Reforma Tributaria 1739 del 23 de diciembre de 2014, Artículo 21, se estableció que "No serán sujetos pasivos de esta sobretasa al impuesto sobre la renta para la actividad CREE, los usuarios calificados y autorizados para operar en las zonas francas costa afuera". Asimismo, en el Decreto 2682 del 23 de diciembre de 2014 del Ministerio de Comercio, Industria y Turismo, se establece que "podrá declararse la existencia de Zonas Francas Permanentes en cualquier parte del territorio nacional costa afuera dedicadas exclusivamente a las actividades de evaluación técnica, exploración y producción de hidrocarburos costa afuera, así como las actividades de logística, comprensión, transformación, licuefacción de gas y demás actividades directamente relacionadas con el sector de hidrocarburos costa afuera". Para dar cumplimiento a lo anterior se establece que "el área solicitada corresponda al área asignada en el contrato suscrito con la Agencia Nacional de Hidrocarburos".
} 


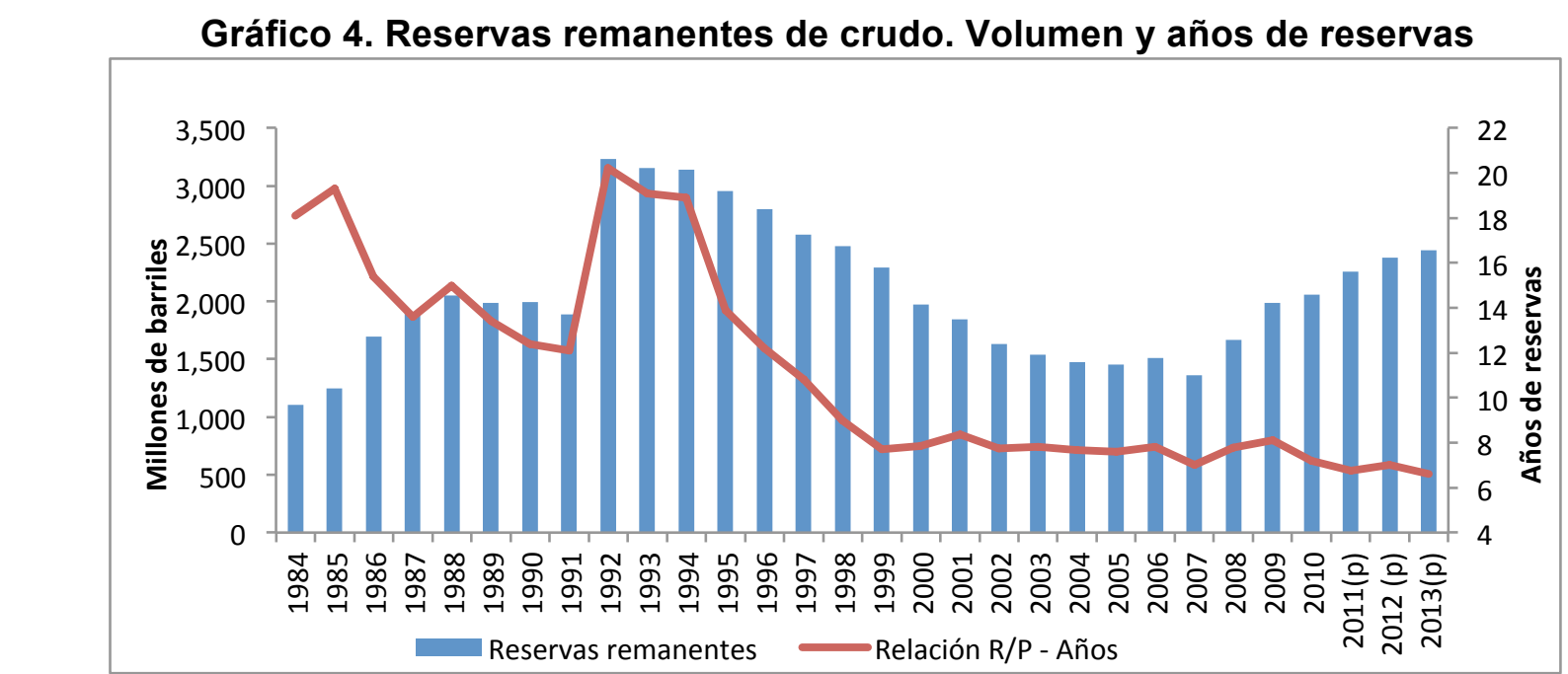

Fuentes: Tomado del IEP-ACP. Ecopetrol, ANH.

\subsection{La importancia del sector del petróleo en la economía colombiana}

Como se señalara anteriormente, el petróleo representa un sector importante para la economía colombiana en cuanto a su contribución al PIB, a la generación de ingresos fiscales para el gobierno (ingresos derivados de impuestos y ganancias de Ecopetrol a través de los dividendos que reparte entre sus socios) y por liquidación de regalías derivadas del petróleo. Estas regalías hoy en día se reparten tanto en las regiones petroleras como en los fondos de compensación para regiones no petroleras, contribuyendo un porcentaje al fondo pensional y con aportes al fondo de compensación (distribución de recursos de las regiones más petroleras a regiones no petroleras), al fondo de estabilización, al fondo de ciencia y tecnología, entre otros. Además, el petróleo genera ingresos derivados de las exportaciones del crudo.

En el esquema 1 se presenta la distribución de la importancia del petróleo en la economía y en los ingresos del Estado. Estos vínculos se expresan de la siguiente manera: en 2011 el PIB petrolero representó el 5,0\% del PIB del país. Cabe notar, como se muestra en el gráfico 5, que los ingresos recaudados por la nación por cuenta del impuesto sobre la renta derivado de la actividad petrolera representan una participación de cerca del 4,3\% con relación a los ingresos totales provenientes del impuesto sobre la renta (imporrenta) total de la economía, y en cuanto a las exportaciones de petróleo, estas representan cerca de un $22 \%$ sobre la exportaciones totales de la economía. A su vez, en el gráfico 6 se muestra la importancia del sector petrolero dentro de las rentas estatales: los recursos provenientes de regalías, impuestos, dividendos y derechos económicos y de aportes al gobierno central. Cabe señalar que los recursos de las regalías han venido aumentando con el crecimiento de los precios del crudo y de los ingresos ya señalados. 
Esquema 1. Vínculos del sector petróleo con la economía nacional

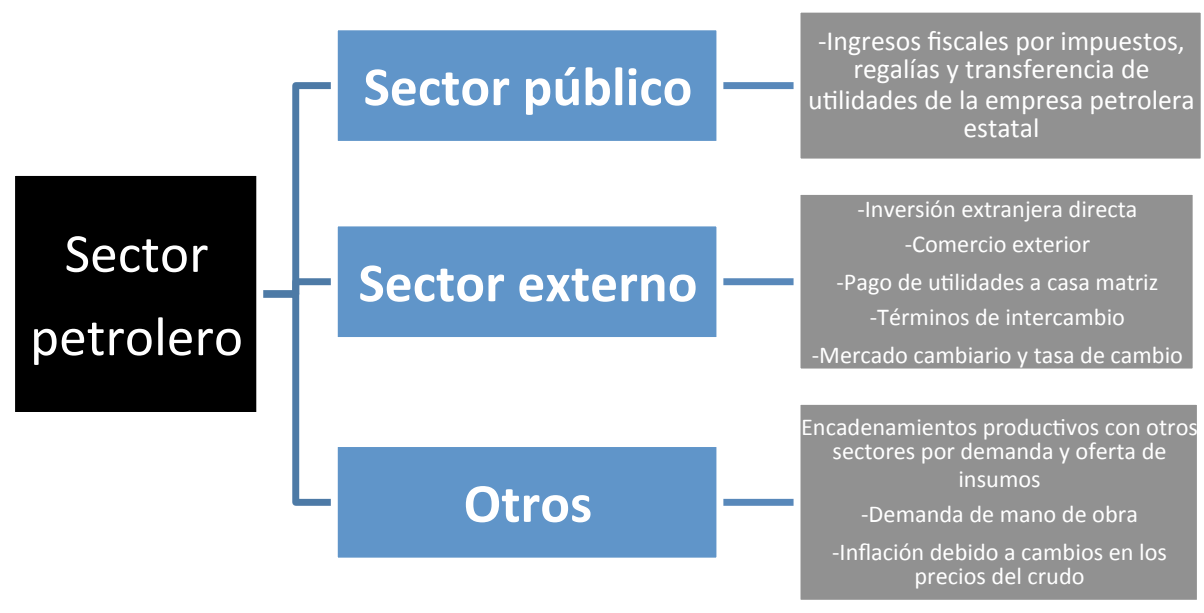

Fuente: López et al. (2013: 3).

Gráfico 5. Importancia del petróleo en Colombia

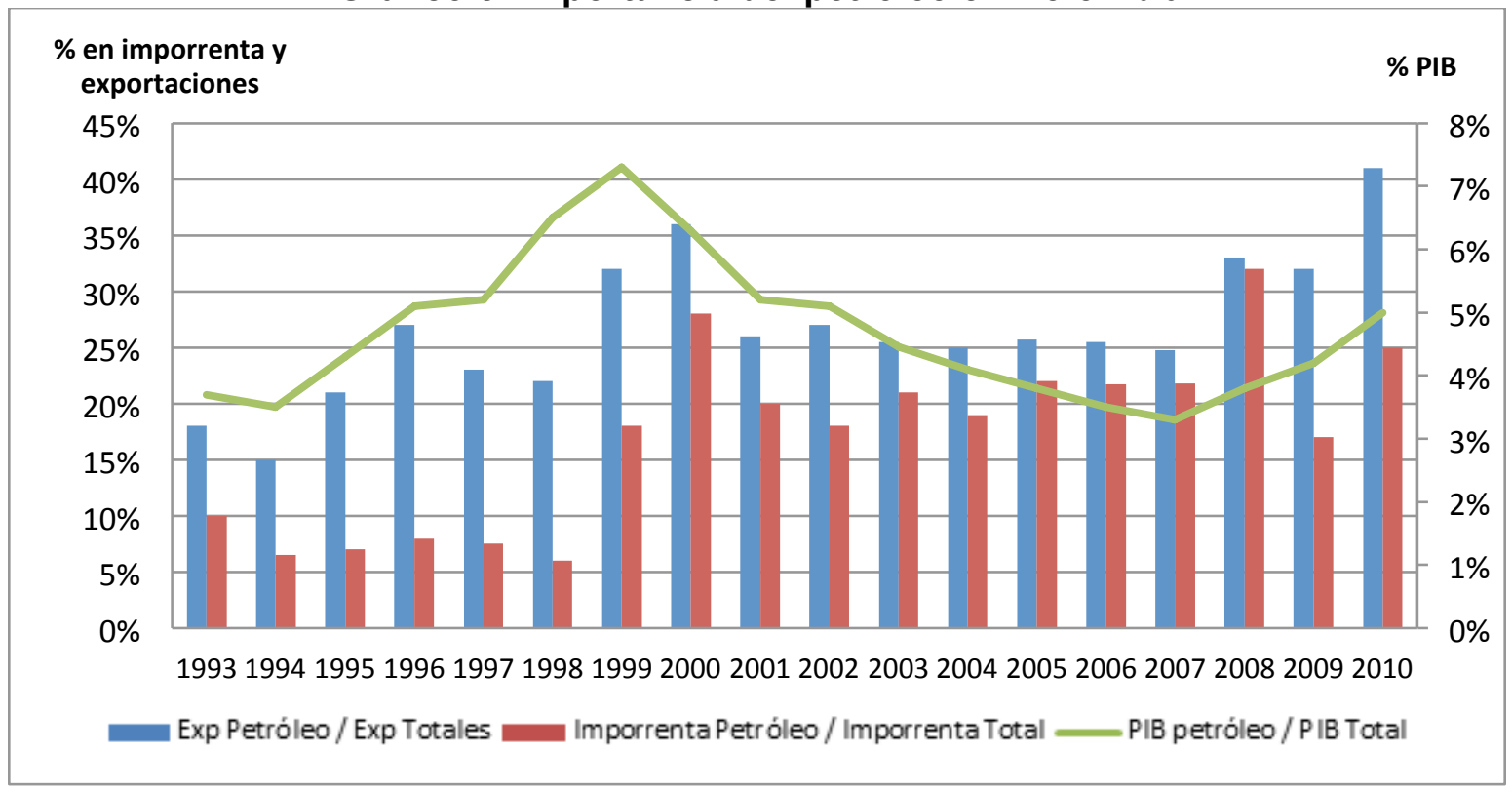

Fuente: López et al. (2013: 3). 
Gráfico 6. Participación en la renta estatal (en billones de pesos)

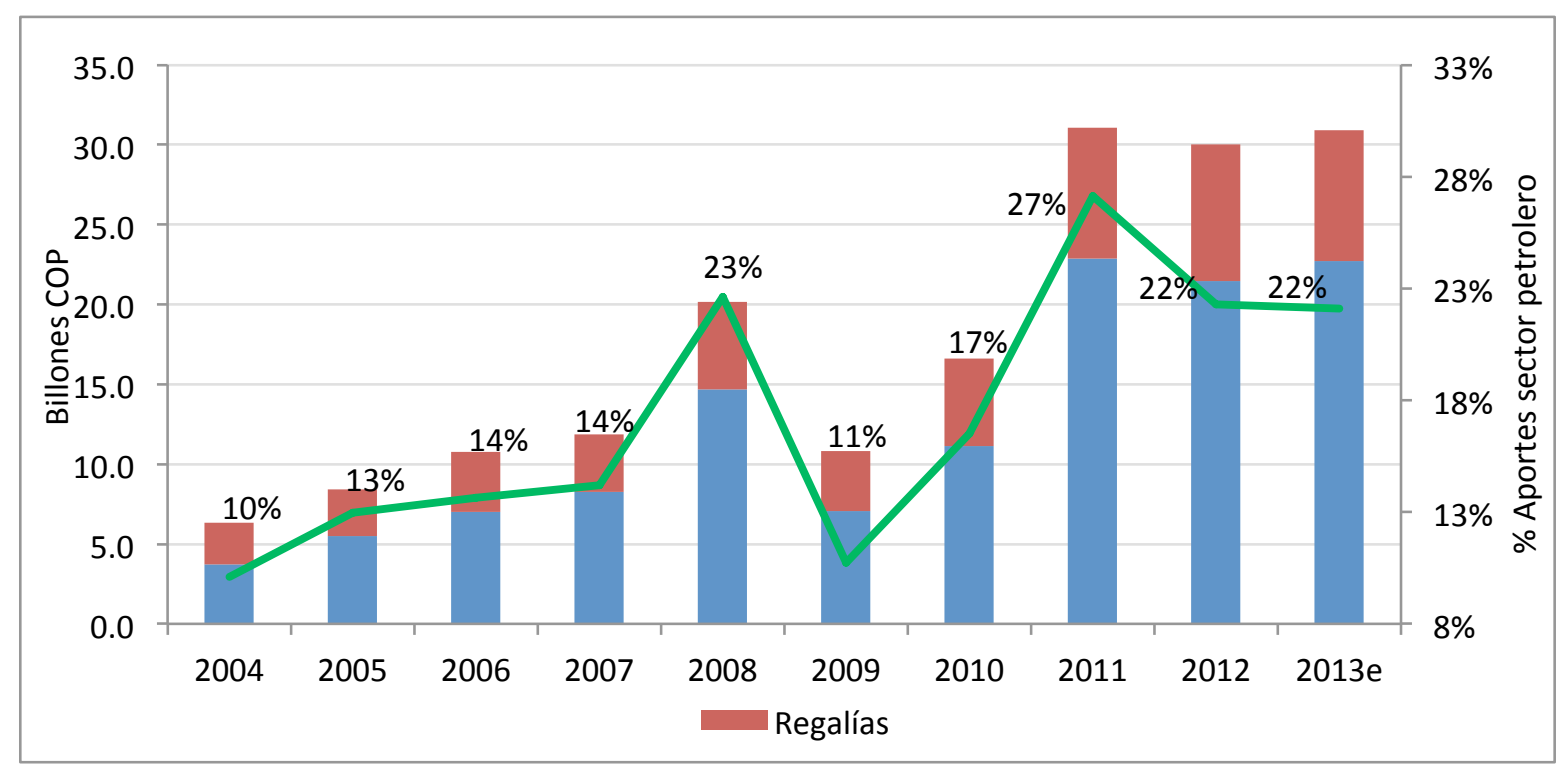

Fuentes: Tomado del IEP-ACP. DIAN, ANH, Minhacienda.

Por otra parte, hay que destacar el papel de la inversión extranjera directa (IED): la participación del sector petrolero en la inversión extranjera directa total de la economía es de cerca del 30\%. Como lo indica el estudio de López et al. (2013: 20), la dependencia del capital extranjero se estabiliza o se atenúa un poco debido a aumentos del capital nacional. "Las entradas de capital extranjero bajo la forma de IED están impulsadas principalmente por el comportamiento del precio internacional y las reglas de juego establecidas en el marco contractual y legal bajo el que opera el sector privado. El nivel de IED se refleja básicamente en la dinámica de la actividad exploratoria, que cubre la ejecución de estudios sísmicos y la perforación de pozos exploratorios (denominados "A3"). Adicionalmente se reciben recursos extranjeros para el montaje de la infraestructura de transporte y de producción".

La relación de flujos de inversión extranjera directa e indicadores de la actividad exploratoria puede observarse en el gráfico 7, en el que se muestra el papel de la inversión extranjera directa, en cuanto a actividades de sísmica, contratos firmados y perforación de pozos exploratorios tipo "A3". Cabe notar que muchas de las variables consideradas son muy sensibles al comportamiento de los precios a nivel internacional. 


\section{Gráfico 7. Indicadores de la actividad exploratoria y flujos de inversión extranjera directa $(U S \$ / b l)$}

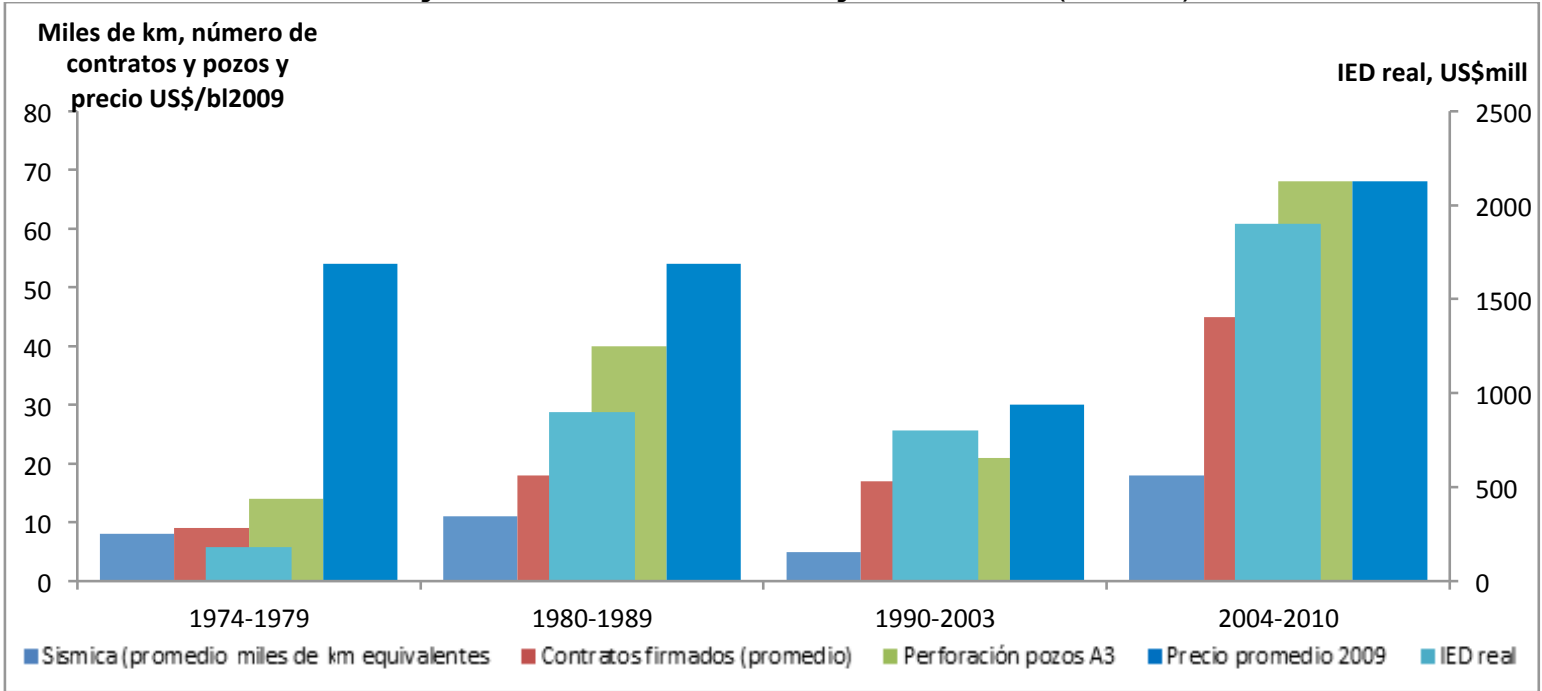

Fuente: López et al. (2013: 20).

Desde la perspectiva de largo plazo, a partir de un estudio llevado a cabo en 2012 sobre escenarios de oferta y demanda de hidrocarburos en Colombia, la Unidad de Planeación Minero Energética realizó un análisis de construcción de escenarios determinando variables y factores críticos para desarrollar políticas públicas al respecto. El estudio tomó cinco fuentes de recursos para la realización de proyecciones de "incorporación de reservas y desarrollo de perfiles de producción": a) reservas probadas en producción de yacimientos convencionales; b) reservas a adicionar por recuperación mejorada; c) reservas no desarrolladas; d) incorporación de otros recursos convencionales potenciales: gas offshore y crudos pesados no descubiertos, y e) recursos no convencionales. Los factores de éxito y las variables críticas actuales y futuras se presentan en el esquema 2, que orienta hacia dónde debe concentrarse la política pública y algunos de sus instrumentos.

Se estima que Colombia tiene perspectivas interesantes para incorporar y desarrollar nuevos crudos en el mediano y largo plazo en una cantidad superior cercana a los 9.000 millones de barriles. Como se analiza más adelante, este escenario potencial dependerá en gran parte de la orientación y prioridad de la política pública; sin embargo, dadas las circunstancias actuales, el primer ajuste está orientado a restringir inversiones en exploración. 


\section{Esquema 2. Matriz de impacto e incertidumbre para escenarios}

FACTORES DE ÉXITO DEL SECTOR
DE HIDROCARBUROS
1. Aumento de la inversión en el
sector promovida por un marco
regulatorio favorable y promoción
internacional
2. Apertura de oportunidades de
inversión bajo distintos esquemas de
negocio
3. Éxito exploratorio e incremento del
conocimiento geológico
4. Modernización de ECOPETROL
e incorporación de recurso humano
calificado
5. Disponibilidad de infraestructura
heredada de la década pasada, pre-
vio a la declinación de producción
6. Mayor productividad por la
inclusión de nuevos esquemas de
perforación
7. Aumento de factor de recobro
en cuencas maduras por el uso de
nuevas tecnologías
8. Mercado intemacional favorable y
altos precios de crudo
9. Mejora en seguridad del país.

\section{VARIABLES CRIITICAS ACTUALES Y} FUTURAS

1. Hallazgos de hidrocarburos convencionales (crudo y gas)

2. Potencial de crudos pesados (especialmente en la cuencas de Los Llanos)

3. Potencial de no convencionales (gas asociado al carbón, shale gas, shale oil, arenas bituminosas)

4. Factor de recobro de hidrocarburos

5. Precio internacional de energéticos (precio de referencia del barril de crudo)

6. Política estatal petrolera (government take)

7. Factores medio ambientales (restricción de la actividad de E\&P por razones ambientales)

8. Factores socio culturales, nivel de conflicto (restricción de la actividad de E\&P por razones sociales

Fuente: UPME (2012: 9).

\subsection{Impactos de la dinámica del sector petrolero sobre las capacidades tecnológicas y los recursos humanos}

Como se expresó anteriormente, la dinámica creciente del sector en los últimos años también tiene un impacto sobre la demanda de fuerza de trabajo calificado que pueda llevar a cabo las actividades tanto en la parte de la explotación del recurso natural como en los servicios intensivos en conocimiento derivados de ella. En este trabajo se analiza dicho impacto a través del comportamiento de diferentes indicadores en la demanda por carreras profesionales asociadas a la actividad petrolera y sus servicios. Se utilizan los registros oficiales del Sistema Nacional de Información de la Educación Superior (SNIES) del Ministerio de Educación Nacional para 4 carreras profesionales que se consideran conectadas de manera directa con las actividades del sector, a saber: Geología, Ingeniería de Petróleos, Ingeniería Geológica e Ingeniería Forestal. Por otro lado, también se observa el comportamiento de 3 maestrías en el sector y 4 especializaciones, a saber: maestrías en Ingeniería de Hidrocarburos, Ciencias Geológicas e Ingeniería Ambiental, y las especializaciones en Gerencia de Hidrocarburos, Ingeniería del Gas, Producción de Hidrocarburos y Derecho Minero y Energético. 
Las estadísticas del Ministerio de Educación entre 2007 y 2013 presentan un crecimiento constante en este período en los estudiantes matriculados en el primer curso de los pregrados relacionados con el sector, pasando de 1541 a 1982 matriculados. De este número, Ingeniería de Petróleos representa cerca del $35 \%$ de los estudiantes, y su comportamiento se ha mantenido más o menos constante a lo largo del período. Sin embargo, se observa un incremento más pronunciado de nuevos estudiantes en Ingeniería Geológica y la profesión de Geología, las cuales pueden estar asociadas de manera más directa a la prestación de bienes y servicios en el sector. Con respecto a las maestrías, el crecimiento ha sido mucho más pronunciado, pasando de 88 estudiantes matriculados en el primer curso en 2007 a cerca de 540 nuevos estudiantes para 2013, y los niveles de especialización presentan una dinámica similar. Por el lado de la oferta de programas destinados a capacitar mano de obra para el sector se observan especializaciones como la de Derecho Minero y Energético y la de Gerencia de Hidrocarburos que pueden afectar de manera directa en las actividades de la industria de bienes y servicios petroleros. De este modo, pueden observarse tendencias de un aumento de la mano de obra técnica del sector y una actualización en la calidad de la misma dado el aumento en los estudiantes a nivel de especializaciones y maestrías (véase el cuadro 2).

\section{Cuadro 2. Evolución de la entrada de nuevos estudiantes (primer curso ${ }^{a}$ ) en pregrados, especializaciones y maestría relacionadas con el sector}

\begin{tabular}{|l|c|c|c|c|c|c|c|}
\cline { 2 - 8 } \multicolumn{1}{c|}{} & $\mathbf{2 0 0 7}$ & $\mathbf{2 0 0 8}$ & $\mathbf{2 0 0 9}$ & $\mathbf{2 0 1 0}$ & $\mathbf{2 0 1 1}$ & $\mathbf{2 0 1 2}$ & $\mathbf{2 0 1 3}$ \\
\hline Geología & 287 & 278 & 307 & 408 & 390 & 359 & 400 \\
\hline Ingeniería de Petróleos & 627 & 632 & 646 & 765 & 676 & 676 & 678 \\
\hline Ingeniería Geológica & 243 & 167 & 181 & 204 & 216 & 273 & 335 \\
\hline SUBTOTAL PREGRADO & $\mathbf{1 1 5 7}$ & $\mathbf{1 0 7 7}$ & $\mathbf{1 1 3 4}$ & $\mathbf{1 3 7 7}$ & $\mathbf{1 2 8 2}$ & $\mathbf{1 3 0 8}$ & $\mathbf{1 4 1 3}$ \\
\hline Maestría en Ingeniería de Hidrocarburos & 0 & 6 & 8 & 3 & 6 & 9 & 3 \\
\hline Maestría en Ciencias - Geología & 21 & 10 & 17 & 23 & 9 & 23 & 16 \\
\hline Maestría en Ciencias de la Tierra & 8 & 0 & 20 & 19 & 24 & 6 & 2 \\
\hline Maestría en Geología & 0 & 0 & 0 & 0 & 16 & 0 & 15 \\
\hline SUBTOTAL MAESTRíA & $\mathbf{2 9}$ & $\mathbf{1 6}$ & $\mathbf{4 5}$ & $\mathbf{4 5}$ & $\mathbf{5 5}$ & $\mathbf{3 8}$ & $\mathbf{3 6}$ \\
\hline Especialización Gerencia Hidrocarburos & 0 & 1 & 14 & 1 & 61 & 34 & 9 \\
\hline Especialización Ingeniería del Gas & 0 & 1 & 14 & 1 & 61 & 34 & 9 \\
\hline Especialización en Producción Hidrocarburos & 0 & 0 & 29 & 0 & 48 & 53 & 22 \\
\hline Especialización en Derecho Minero y Energético & 0 & 22 & 0 & 50 & 80 & 78 & 59 \\
\hline SUBTOTAL ESPECIALIZACIÓN & $\mathbf{0}$ & $\mathbf{2 4}$ & $\mathbf{5 7}$ & $\mathbf{5 2}$ & $\mathbf{2 5 0}$ & $\mathbf{1 9 9}$ & $\mathbf{9 9}$ \\
\hline TOTAL & $\mathbf{1 1 8 6}$ & $\mathbf{1 1 1 7}$ & $\mathbf{1 2 3 6}$ & $\mathbf{1 4 7 4}$ & $\mathbf{1 5 8 7}$ & $\mathbf{1 5 4 5}$ & $\mathbf{1 5 4 8}$ \\
\hline
\end{tabular}

Fuente: SNIES

a Primer Curso: Persona natural que formaliza su matrícula en primer curso en el programa académico que fue admitido.

En el cuadro 3 se muestra el comportamiento del número anual de matriculados tanto a nivel de pregrado como de maestría y especializaciones en las áreas de mayor relación con la industria del sector del petróleo. Hay que destacar que el recurso humano en Ingeniería de 
Petróleos solo puede formarse en 4 universidades del país que ofrecen esta carrera, lo cual hace que esta profesión presente un mercado muy concentrado y con muy baja dispersión en la institucionalidad del sector de educación superior, que está conformado por un gran número de instituciones.

Por otra parte, cabe notar que de acuerdo con datos del Observatorio del Mercado Laboral para los períodos comprendidos entre 2006 y 2011, dentro de las áreas de formación seleccionadas y con relación al sector, el mercado de los ingenieros de petróleo es el de mayor salario para el primer año de vinculación después de su graduación y para los dos años subsiguientes, tanto para los pregrados, como para los profesionales con maestría y especialización.

Cuadro 3. Evolución de la matrícula anual en pregrados, especializaciones y maestría relacionadas con el sector

\begin{tabular}{|l|r|r|r|r|r|r|}
\cline { 2 - 6 } \multicolumn{1}{l|}{} & $\mathbf{2 0 0 8}$ & $\mathbf{2 0 0 9}$ & $\mathbf{2 0 1 0}$ & $\mathbf{2 0 1 1}$ & $\mathbf{2 0 1 2}$ & $\mathbf{2 0 1 3}$ \\
\hline Geología & 2358 & 2482 & 2763 & 2976 & 3267 & 3583 \\
\hline Ingeniería de Petróleos & 5819 & 6294 & 6779 & 7211 & 7409 & 7470 \\
\hline Ingeniería Geológica & 1182 & 1246 & 1309 & 1474 & 1840 & 2171 \\
\hline SUBTOTAL PREGRADO & $\mathbf{9 3 5 9}$ & $\mathbf{1 0 0 2 2}$ & $\mathbf{1 0 8 5 1}$ & $\mathbf{1 1 6 6 1}$ & $\mathbf{1 2 5 1 6}$ & $\mathbf{1 3 2 2 4}$ \\
\hline Maestría en Ingeniería de Hidrocarburos & 9 & 28 & 34 & 37 & 38 & 37 \\
\hline Maestría en Ciencias - Geología & 66 & 69 & 91 & 68 & 73 & 76 \\
\hline Maestría en Ciencias de la Tierra & 7 & 68 & 61 & 72 & 25 & 11 \\
\hline Maestría en Geología & 30 & 30 & 16 & 20 & 30 & 47 \\
\hline SUBTOTAL MAESTRíA & $\mathbf{1 1 2}$ & $\mathbf{1 9 5}$ & $\mathbf{2 0 2}$ & $\mathbf{1 9 7}$ & $\mathbf{1 6 6}$ & $\mathbf{1 7 1}$ \\
\hline Especialización Gerencia Hidrocarburos & 35 & 54 & 75 & 221 & 274 & 113 \\
\hline Especialización Ingeniería del Gas & 35 & 54 & 75 & 221 & 274 & 113 \\
\hline Especialización en Producción Hidrocarburos & 30 & 106 & 74 & 70 & 171 & 22 \\
\hline Especialización en Derecho Minero y Energético & 22 & 25 & 112 & 140 & 182 & 157 \\
\hline SUBTOTAL ESPECIALIZACIÓN & $\mathbf{1 2 2}$ & $\mathbf{2 3 9}$ & $\mathbf{3 3 6}$ & $\mathbf{6 5 2}$ & $\mathbf{9 0 1}$ & $\mathbf{4 0 5}$ \\
\hline TOTAL & $\mathbf{9 5 9 3}$ & $\mathbf{1 0 4 5 6}$ & $\mathbf{1 1 3 8 9}$ & $\mathbf{1 2 5 1 0}$ & $\mathbf{1 3 5 8 3}$ & $\mathbf{1 3 8 0 0}$ \\
\hline
\end{tabular}

Fuente: SNIES.

No obstante, existen retos actuales de acuerdo con la nueva dinámica de los precios internacionales del petróleo y el decrecimiento del tamaño del mercado. En un estudio contratado por la Asociación Colombiana de Ingenieros de Petróleo (ACIPET), los analistas destacan que los ingenieros de petróleo están enfrentando actualmente altas tasas de desempleo, significativamente por encima de las tasas promedio de la economía, y una percepción negativa sobre las posibilidades de empleabilidad. El estudio señala que el mayor campo de vinculación de los ingenieros de petróleo graduados en los tres últimos años, se ha dado en el área de servicios petroleros $(45 \%)$ más que en el área de operación (24\%). Cuando se analiza el mercado laboral de los ingenieros de petróleo con más de tres años de graduados se encuentra que el porcentaje de vinculación a empresas operadoras es del 33\% y a las empresas de servicios petroleros es del $32 \%$, siguiendo en orden el sector de transporte de hidrocarburos con un $12 \%$, el sector de refinación con un $8 \%$ y el de comercialización con $1 \%$. 
Dado el contexto de crisis actual, pero a la vez con la necesidad de contar con un mayor nivel de formación de recursos humanos en áreas más complejas como el offshore, la recuperación de campos secundarios y terciarios y la exploración y explotación de yacimientos no convencionales, se está desarrollando una política pública de formación a nivel de doctorado y maestría en el exterior a través de un convenio recientemente firmado entre Colciencias y la Agencia Nacional de Hidrocarburos. Estas dos instituciones han lanzado una convocatoria pública para financiar la formación de profesionales a nivel de maestría y doctorado en el exterior con un fondo de recursos disponible de Col $\$ 3.000$ millones para doctorado y Col\$1.500 millones para estudios de maestría. Esta primera convocatoria será para que los beneficiados de las becas inicien sus respectivos estudios en el primer semestre de 2016. Las becas están orientadas a estudios e investigación en 7 áreas principales: a) Operaciones offshore; b) Yacimientos no convencionales; c) Regulación de hidrocarburos; d) Competitividad y negocios de hidrocarburos; e) Responsabilidad social y ambiental; f) Exploración de hidrocarburos, y g) Explotación de hidrocarburos.

\section{El estado actual de la industria de servicios en la producción de petróleo en Colombia}

\subsection{La cadena de valor del sector de hidrocarburos y la identificación de los servicios}

En esta sección se presenta la cadena de valor del recurso natural que se estudia. Su objetivo es describir de manera detallada la forma organizacional de las empresas, su papel dentro de la cadena de valor, los servicios que se generan y su base industrial. La cadena de valor expresada en el esquema 3 describe de manera amplia los servicios asociados y derivados del sector de hidrocarburos. En este sector se ha dado desde hace varias décadas una desintegración vertical y el surgimiento de nuevos servicios como producto de nuevos avances tecnológicos y nuevas oportunidades del desarrollo local.

En la primera etapa de la cadena de valor (el recuadro marrón a la izquierda del esquema 3) se identifican los servicios de las fases de exploración y de evaluación y desarrollo, que son actividades de servicios que se realizan para poder identificar la existencia de yacimientos y que definen la tipología del yacimiento y el contenido del mismo. Las características del terreno, y por lo tanto del yacimiento, determinan en gran medida los retos de innovación y de desarrollo tecnológico que se dan en esta fase. En una segunda etapa (el recuadro azul en el centro), después del yacimiento, se generan servicios en la fase de desarrollo y producción. Dichos servicios están igualmente determinados en sus aspectos tecnológicos por las características del yacimiento y del tipo de crudo que se explota. Una vez obtenido el crudo, se encuentra la cadena de transporte, almacenamiento y comercialización del mismo (el recuadro verde en el extremo derecho del esquema 3). En esta etapa final de la cadena de valor también se presentan los servicios de refinamiento y petroquímicas. ${ }^{3}$

\footnotetext{
${ }^{3}$ Existen servicios que no forman parte exclusiva de la cadena de valor del hidrocarburo; estos se clasifican en bienes y servicios transversales.
} 
Después de que se lograron esquematizar las diferentes etapas de la cadena de valor, mediante entrevistas y consultas a las principales empresas prestadoras de servicios, empresas operadoras y la agremiación de proveedores de servicios (Campetrol), se detallaron y se describieron los servicios existentes en cada etapa de la cadena de valor (véase el esquema 3 para una enumeración detallada de dichos servicios). En total, se identificó un mercado de 59 servicios ofrecidos en la industria colombiana de servicios de hidrocarburos. La distribución de estos servicios depende de las etapas a la que pertenezcan. En las etapas de descubrimiento y manejo de yacimientos se identificaron 34 servicios; de ellos, la etapa de exploración cuenta con 9 líneas de negocios, y la etapa de evaluación y desarrollo, con 18 líneas de negocios, de las cuales el conjunto de perforación agrupa 7 servicios y las líneas de servicios complementarios agrupan 5 servicios. La etapa de desarrollo y producción presenta 7 tipos de servicios. En la tercera etapa del manejo del crudo, el transporte incluye tres grupos diferentes: oleoductos (con 4 servicios), gaseoductos (con 4 servicios) y poliductos (con 5 servicios), que componen 13 tipos de servicios. En el almacenamiento y comercialización del crudo se generan 4 servicios. Finalmente, en refinación y petroquímicas se cuentan 8 servicios. ${ }^{4}$

Existe una línea externa de negocios que complementa toda la cadena de valor y es la de bienes y servicios transversales. Las diferencias por retos tecnológicos y de innovación son bastante variadas en cada etapa, y dentro de cada etapa sus líneas de servicios también difieren en los requisitos de conocimiento e innovación. Estas diferencias pueden determinar de manera significativa el número de empresas que entran al sector y establecer características especiales de las mismas basadas en su experiencia y conocimiento (know-how), lo cual, a su vez, puede limitar la entrada a las empresas que satisfagan dichos requisitos.

\footnotetext{
${ }^{4}$ Estos mercados se caracterizan por barreras tecnológicas diferentes y competencias específicas que plantean retos tecnológicos a las empresas que deciden prestar en ellas sus servicios, lo cual se puede manifestar en barreras al ingreso de varias empresas.
} 


\section{Esquema 3}

\section{CADENA DE VALOR DE LOS SERVICIOS EN EL SECTOR DE HIDROCARBUROS}

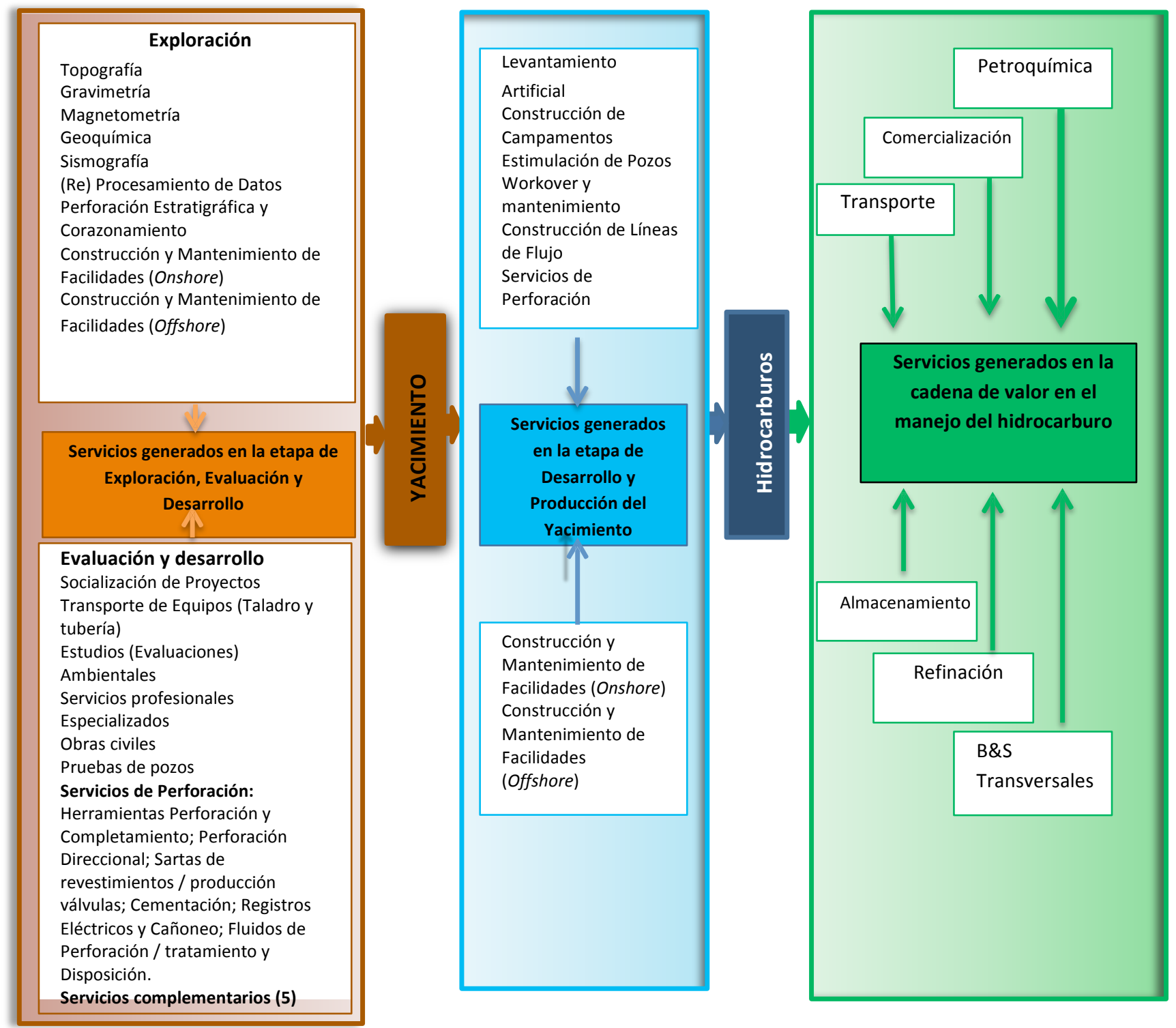

Fuente: Elaboración de los autores basado en información de la Cámara Colombiana de Bienes y Servicios Petroleros, CAMPETROL - Directorio 2014. 
Como se mencionó anteriormente, existe una participación activa de empresas multinacionales tanto operadoras como prestadoras de servicios en el sector y por lo tanto es importante entender la estructura de operación de dichas firmas en el país. En general, las firmas extranjeras crean una sucursal en el país para el desarrollo de su actividad, estableciendo operaciones entre la casa matriz y la sucursal en Colombia. La relación entre la casa matriz y su sucursal está definida tanto por la constitución de la empresa, como por la etapa de exploración y por la etapa de producción y explotación. En cada fase de operación hay múltiples modalidades de trabajo y relación, ya que la matriz puede contratar en el exterior servicios técnicos especializados (en el caso de exploración), pero también puede contratar a firmas de servicios con valor agregado de conocimiento extranjeras establecidas en Colombia o firmas nacionales que tengan ese valor agregado. Además, la casa matriz también acostumbra enviar equipos especializados, que según la nueva legislación, particularmente en la que se asigna carácter de zona franca cuando la actividad se va a realizar offshore puede importarse libre de gravámenes y de rentas (López et al., 2012).

\subsection{Participación de la empresas prestadoras de servicios en la cadena de valor}

En esta cadena de valor se identificaron 181 empresas inscritas como potencialmente prestadoras de servicios para uno o más de los servicios identificados, y las cuales se encuentran registradas en la Cámara de Comercio de Hidrocarburos, Campetrol. No obstante, de las 181 empresas inscritas se identificaron a 22 que no participan en la provisión de servicios en ninguna etapa de la cadena de valor; por lo tanto, se pudieron ubicar 159 que prestaban al menos un servicio en el sector. El estudio tomó como base a estas 159 empresas para caracterizar su presencia en cada etapa de la industria. ${ }^{5}$

El cuadro 4 presenta las estadísticas generales de dichas empresas. El 57\% de las empresas reportaron un origen de capital nacional frente a un $43 \%$ extranjero, donde la mayor parte son empresas subsidiarias de una multinacional que opera en el mercado local colombiano. Además, las empresas pueden caracterizarse según tres dimensiones que son importantes para entender mejor la estructura de la industria de servicios petroleros en Colombia, a saber: años de experiencia, número de empleados y número de clientes. La primera dimensión se refiere a los años de operación de la empresa (debe notarse que la mayor parte de años de operación reportados hacen referencia a la experiencia de la multinacional y no de la subsidiaria en Colombia), lo cual tiene sentido dada la acumulación de conocimiento y tecnología. El segundo aspecto de caracterización es el tamaño de la empresa, que incluye en algunos casos el personal de empresas subsidiarias pero en menor medida. Esta dimensión puede subdividirse en cuatro categorías: microempresas (menos de 10 empleados), pequeñas (entre 11 y 50 empleados), medianas (entre 51 y 200

\footnotetext{
${ }^{5}$ Es importante notar que de las 22 empresas no identificadas, la mayor parte estaban relacionadas con servicios de aseguramiento, legales y de profesionales de aduanas, todos contenidos en la fase de bienes y servicios transversales.
} 
empleados) y grandes (más de 200 empleados). Una tercera forma de caracterización es el número de clientes, y depende de la información que reportan las empresas sobre este aspecto.

\section{Cuadro 4}

Características generales de las empresas proveedoras de servicios en la cadena de valor de hidrocarburos

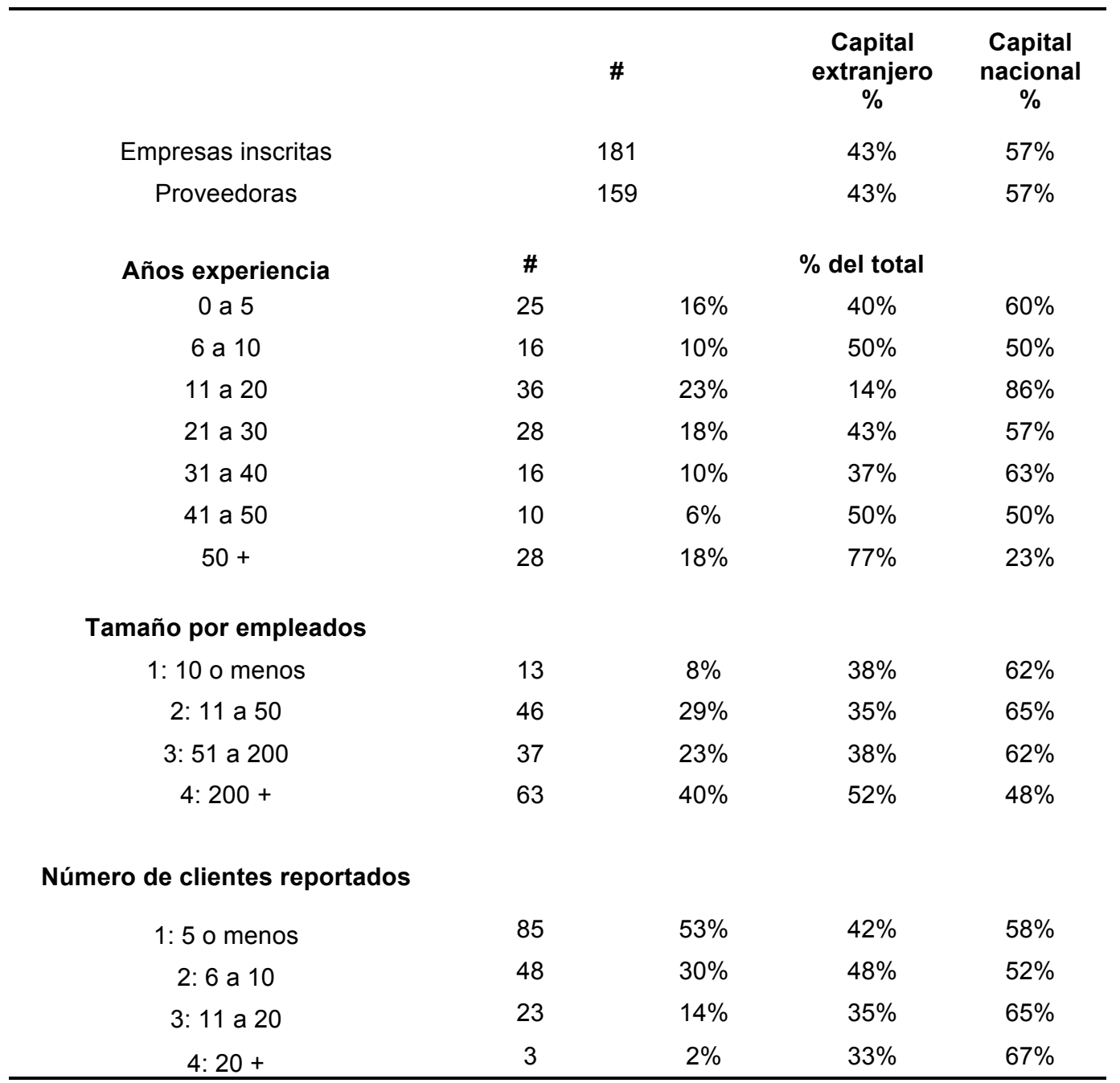

Fuentes: Directorio Campetrol y cálculo de los autores.

Al analizar los años de experiencia, se observa que el $26 \%$ de las empresas tienen menos de 10 años de experiencia en la industria de hidrocarburos, y el 23\% cuentan con una experiencia de entre 11 y 20 años. El resto de las empresas (51\%) cuentan con más de 20 años de experiencia. Por lo tanto, Colombia cuenta con un sector de hidrocarburos caracterizado por empresas con amplia experiencia. No obstante, es importante destacar que la cuarta parte de las empresas que existen actualmente fueron creadas en los últimos 10 años, lo que coincide con el período de más dinamismo de la industria de petróleo en el país. 
Cuando se observan estas mismas estadísticas por tipo de capital, se identifica una llegada más amplia de empresas de capital extranjero en los últimos 5 años. Esto se puede reforzar al considerar que las empresas con experiencia de entre 10 y 40 años son predominantemente nacionales y solo aquellas con una trayectoria superior a los 50 años son en su mayoría extranjeras, lo cual está relacionado con la existencia de las grandes multinacionales del sector que fueron creadas varias décadas atrás.

Con respecto al tamaño, las empresas que participan en el mercado son predominantemente grandes, y representa el $40 \%$ de la industria de servicios. Las empresas medianas y grandes constituyen casi el $63 \%$. Solo el $37 \%$ son empresas pequeñas. Por otra parte, cuando se observan el tamaño de la empresa y el capital extranjero, se nota que las empresas grandes son las que cuentan principalmente con capital de origen extranjero, mientras que las empresas pequeñas o medianas se manejan con capital nacional.

Asimismo, puede observarse la distribución de las empresas por el número de clientes con los cuales tienen negocios. Las empresas reportaron tener en promedio 5,7 clientes, con una desviación estándar de 5,4. Dado que existen diferencias importantes en el número de clientes entre estas empresas, se las clasificó en cuatro grupos: con 5 clientes o menos, entre 6 y 10 clientes, entre 11 y 20 clientes y más de 20 clientes. Es importante notar los diferentes tipo de clientes posibles: operadores del recurso natural (dueños de yacimiento y crudo), empresas de servicios del sector y otros clientes de industrias afines al sector, o en el caso de catering y de energía, diversos tipos de industrias. El $53 \%$ de las empresas están concentradas en el promedio del número de clientes, cerca de 5 o menos. El $30 \%$ entre 6 y 10, el $14 \%$ entre 11 y 20 , y solo unas pocas empresas $(2 \%)$ tienen más de 20 clientes. No existen diferencias importantes en la distribución del origen del capital de la empresa cuando se observa por número de clientes.

A manera de resumen, las empresas proveedoras de servicios en la cadena de valor de hidrocarburos pueden caracterizarse como una industria que tiene un porcentaje de participación extranjera significativa, con empresas de amplia trayectoria en esta industria, tanto a nivel nacional como internacional, y de gran tamaño. Algunas empresas fueron creadas recientemente con una entrada de capital extranjero levemente superior al promedio de la industria. Finalmente, existe una conectividad adecuada entre los proveedores de servicios.

Como ya se mencionó, el capital del $43 \%$ de las 159 empresas analizadas es de origen extranjero y el capital del resto es de origen nacional. En cuanto a la concentración de mercado por origen de capital, cabe notar que aunque el $57 \%$ de las firmas de servicios de hidrocarburos poseen capital de origen nacional, las firmas con capital extranjero proveen servicios al sector de manera más amplia. El gráfico 8 muestra la participación de las firmas por origen de capital en los ingresos operacionales del sector: se observa un alto grado de concentración de los ingresos en las firmas extranjeras correspondiente al 69\%, y el restante $31 \%$ corresponde a los ingresos operacionales generados por empresas 
nacionales, lo que equivale a Col\$8,9 billones y Col\$4,1 billones, respectivamente.

\section{Gráfico 8. Participación en ingresos operacionales Firmas extranjeras vs. firmas nacionales (\%)}

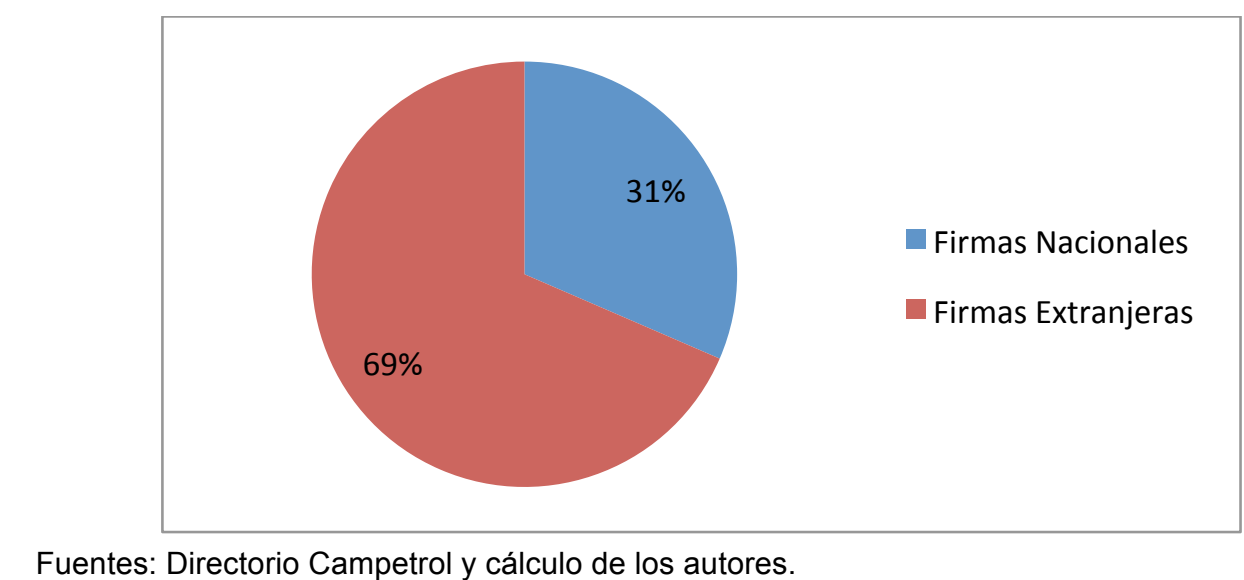

Cuando se observan las estadísticas descriptivas sobre la distribución de activos por origen de capital descritas en el cuadro 5, es claro que existe una diferencia importante en el tamaño de las firmas. En promedio, el nivel de activos de las firmas nacionales es Col $\$ 48.386$ millones, mientras que el de las firmas extranjeras es Col\$133.520 millones, lo cual equivale a casi 3 veces los activos de las empresas nacionales. También debe destacarse que la alta dispersión entre el valor de los activos de las firmas más pequeñas y las firmas más grandes, se mantiene tanto para el caso de las firmas nacionales como para el caso de las firmas extranjeras. En el caso de las firmas nacionales, el valor de los activos de la firma más grande es aproximadamente 362 veces el valor de los activos de la firma más pequeña. Más aún, hay una asimetría en la distribución de los activos entre las firmas nacionales y las firmas de origen extranjero.

El valor de los activos de la firma extranjera más grande es cerca de 4 veces más que el valor de los activos de la firma nacional más grande. Algo similar ocurre cuando se analizan los niveles máximos y mínimos de activos, donde los valores para las empresas con capital extranjero son considerablemente más altos que los de las firmas de capital nacional. Por el contrario, aunque las empresas extranjeras grandes lideran el mercado, también existen algunas empresas extranjeras que son medianas, y unas pocas son pequeñas. Para el caso de las empresas nacionales, la desviación estándar es menor, lo que muestra empresas con tamaños más similares y muy pocas con un alto nivel de activos. 


\section{Cuadro 5}

Estadísticas descriptivas sobre el valor de la distribución de los activos entre firmas nacionales y firmas extranjeras, 2014 (millones de pesos corrientes)

\begin{tabular}{lc}
\multicolumn{2}{c}{$\begin{array}{c}\text { Panel A. Estadísticas del valor de los activos } \\
\text { de las firmas nacionales }\end{array}$} \\
\hline Estadística & Valor \\
Promedio & 48.386 \\
Máximo & 463.071 \\
Mínimo & 387 \\
Desviación estándar & 83.368 \\
Coeficiente de asimetría & 3,04 \\
\hline
\end{tabular}

\begin{tabular}{lc}
\multicolumn{2}{c}{ Panel B. Estadísticas del valor de los activos de } \\
las firmas extranjeras
\end{tabular}

NOTA: Número de empresas: total: 154; nacionales: 87; extranjeras: 67.

Fuentes: Directorio Campetrol y cálculo de los autores.

Los cuadros 6 y 7 presentan la caracterización de los ingresos operacionales y del total de activos para las 10 firmas más grandes del sector de servicios de hidrocarburos, para los años de 2011 y 2014. Se puede afirmar que el tamaño de las firmas es proporcional a la concentración de ingresos que tienen del mercado, ya que las 6 empresas con mayores ingresos operacionales son también las 6 con mayor cantidad de activos. Dentro de este grupo es claro que Shlumberger Surenco S.A. es la empresa líder del mercado: su participación en toda la cadena de valor es amplia y ha mantenido su liderazgo por lo menos desde 2011. Ocurre algo similar a nivel de las empresas de origen nacional con Ingeniería, Servicios, Montajes y Construcción de Oleoductos de Colombia S.A., la cual se encuentra dentro de las 6 empresas con mayores ingresos operacionales desde 2011 y cuyo desempeño le ha permitido pasar de ser la décima empresa por nivel de activos en 2011 a ser la quinta en el año 2014.

Finalmente, es importante resaltar la concentración muy fuerte que existe en el mercado de servicios dentro de la cadena de valor, donde la participación en los ingresos operacionales del sector por parte de las 10 empresas más grandes equivale al 56,81\%, esto quiere decir que las 10 empresas más grandes del mercado concentran más de la mitad de los ingresos de todo el sector, compuesto por más de 150 firmas. Ocurre lo mismo para el análisis del nivel de activos en donde las 10 firmas más grandes concentran el $50,58 \%$ del nivel de activos totales del sector. 


\section{Cuadro 6}

\section{Principales empresas de servicios petroleros en Colombia por ingresos operacionales, 2011 y 2014 (millones de pesos corrientes)}

\begin{tabular}{|c|c|c|c|c|c|}
\hline Empresa & $\begin{array}{c}\text { Ingresos } \\
\text { operacionales } \\
2014\end{array}$ & $\begin{array}{l}\text { Participación } \\
\text { sobre total de } \\
\text { empresas de } \\
\text { servicios } \\
\text { petroleros }(\%)\end{array}$ & $\begin{array}{c}\text { Clasificación } \\
2014\end{array}$ & $\begin{array}{c}\text { Ingresos } \\
\text { operacionales } \\
2011\end{array}$ & $\begin{array}{c}\text { Clasificación } \\
2011\end{array}$ \\
\hline Schlumberger Surenco S.A. & 1.548 .544 & $12 \%$ & 1 & 1.084 .777 & 1 \\
\hline Chicago Bridge \& Iron CBI Colombiana S.A. & 1.157 .509 & $9 \%$ & 2 & - & - \\
\hline Halliburton Latin America S.A LL & 897.101 & $7 \%$ & 3 & 769.546 & 2 \\
\hline Weatherford Colombia Limited & 811.609 & $6 \%$ & 4 & 712.163 & 4 \\
\hline Baker Hughes de Colombia & 694.821 & $5 \%$ & 5 & 569.884 & 5 \\
\hline $\begin{array}{l}\text { Ingeniería, servicios, montajes y construcción } \\
\text { de oleoductos de Colombia S.A. }\end{array}$ & 684.846 & $5 \%$ & 6 & 735.539 & 3 \\
\hline Mecánicos Asociados S.A.S. & 532.397 & $4 \%$ & 7 & 271.721 & 9 \\
\hline Independence Drilling S.A. & 394.252 & $3 \%$ & 8 & 302.985 & 7 \\
\hline Basf Química Colombiana S.A. & 382.713 & $3 \%$ & 9 & - & - \\
\hline San Antonio Internacional Sucursal Colombia & 361.266 & $3 \%$ & 10 & 361.038 & 6 \\
\hline Promedio sector servicios petroleros & 83.432 & & & & \\
\hline Total sector servicios petroleros & 13.140.182 & & & & \\
\hline $\begin{array}{l}\text { Participación de las } 10 \text { empresas } \\
\text { principales sobre el total de empresas }\end{array}$ & $56,81 \%$ & & & & \\
\hline
\end{tabular}

Fuentes: Directorio Campetrol y cálculo de los autores.

\section{Cuadro 7}

Principales empresas de servicios petroleros en Colombia por activos, 2011 y 2014 (millones de pesos corrientes)

\begin{tabular}{|c|c|c|c|c|c|}
\hline Empresa & $\begin{array}{l}\text { Activos } \\
2014\end{array}$ & $\begin{array}{l}\text { Participación } \\
\text { sobre total de } \\
\text { empresas de } \\
\text { servicios } \\
\text { petroleros (\%) }\end{array}$ & $\begin{array}{l}\text { Clasificación } \\
2014\end{array}$ & $\begin{array}{l}\text { Activos } \\
2011\end{array}$ & $\begin{array}{c}\text { Clasificación } \\
2011\end{array}$ \\
\hline Schlumberger Surenco S.A. & 1.988 .393 & $15 \%$ & 1 & 1.097 .573 & 1 \\
\hline Weatherford Colombia Limited & 948.682 & $7 \%$ & 2 & 832.496 & 2 \\
\hline Halliburton Latin America S.A LL & 727.261 & $6 \%$ & 3 & 541.282 & 4 \\
\hline Baker Hughes de Colombia & 547.335 & $4 \%$ & 4 & 359.663 & 8 \\
\hline $\begin{array}{l}\text { Ingeniería, servicios, montajes y construcción } \\
\text { de oleoductos de Colombia S.A. }\end{array}$ & 463.071 & $4 \%$ & 5 & 313.822 & 10 \\
\hline Chicago Bridge \& Iron CBI Colombiana S.A. & 456.580 & $3 \%$ & 6 & - & - \\
\hline Tuscany Internationall Drilling & 429.950 & $3 \%$ & 7 & - & - \\
\hline Independence Drilling S.A. & 409.782 & $3 \%$ & 8 & 319.220 & 9 \\
\hline San Antonio Internacional Sucursal Colombia & 341.066 & $3 \%$ & 9 & 382.284 & 6 \\
\hline Pioneer de Colombia SDAD LTA & 322.822 & $2 \%$ & 10 & - & - \\
\hline Promedio sector servicios petroleros & 93.201 & & & & \\
\hline Total sector servicios petroleros & 13.117.353 & & & & \\
\hline $\begin{array}{l}\text { Participación de las } 10 \text { empresas principales } \\
\text { sobre el total de empresas }\end{array}$ & $50,58 \%$ & & & & \\
\hline
\end{tabular}

Fuentes: Directorio Campetrol y cálculo de los autores. 


\subsection{Distribución de las empresas por la cadena de valor}

Dado que el objetivo es poder identificar la existencia de empresas proveedoras de servicios y, en lo posible, poder saber la existencia de aquellas intensivas en conocimiento, así como las posibilidades de un desarrollo de empresas nacionales con alta productividad, en esta sección se busca describir la distribución de las empresas proveedoras de servicios a lo largo de la cadena de valor. Existen varias observaciones que se desprenden del análisis de los datos. Para la cadena de valor se identificaron 59 servicios o líneas de negocios que las empresas pueden prestar y además, se comprobó que existe un porcentaje importante de empresas que participan en más de un servicio. Estas dimensiones permiten identificar las estadísticas del grado de diversificación de las empresas. De las 159 empresas de servicios sobre las cuales se tiene información que participaron en al menos uno de los 59 tipos de servicios identificados se observa que, en promedio, las empresas participan en 8,5 tipos de servicios. Cuando se analizan los promedios separando la muestra entre las empresas que son de capital extranjero y las de capital nacional, se encuentra que las de capital extranjero ofrecen en promedio un mayor número de servicios $(10,4)$ que las de capital nacional $(7,0)$. También se observa una mayor varianza en el número de servicios ofrecidos por estos tipos de empresas: las de capital extranjero son más diversificadas en el número de servicios ofrecidos en comparación con sus contrapartes nacionales.

Cómo se observa en el cuadro 8, la distribución de las empresas que participan en la cadena de valor es bastante disímil. Para el total de la industria se observa que el $71 \%$ de las empresas ofrecen algún servicio en la fase de evaluación y desarrollo, y el $68 \%$ participan en algún servicio en la fase de desarrollo y producción. Es importante notar que en términos de necesidades existen 18 tipos de servicios que se presentan en la fase de evaluación y desarrollo y solo 7 en la fase de desarrollo y producción. Para la fase de exploración se tienen 9 tipos de servicios y solo el $26 \%$ de las empresas prestan algún servicio en esta etapa de la cadena de valor. Transporte y almacenamiento del crudo generan 16 servicios, y estos son satisfechos solo por el $35 \%$ de las empresas. Para el caso de refinación y petroquímicos, el $28 \%$ de las empresas ofrecen alguno de los 8 servicios que allí se requieren. 


\section{Cuadro 8. Medidas de diversificación de las empresas en la cadena de valor}

\begin{tabular}{|c|c|c|c|c|c|c|c|}
\hline & \multirow{2}{*}{$\begin{array}{l}\text { Promedio } \\
\text { servicios } \\
\text { ofrecidos }\end{array}$} & \multirow{2}{*}{$\begin{array}{c}\text { Variación } \\
\text { (desviación } \\
\text { estándar) }\end{array}$} & \multicolumn{5}{|c|}{$\begin{array}{c}\text { Porcentaje de empresas que ofrecen servicios en cada } \\
\text { fase de la cadena de valor }\end{array}$} \\
\hline & & & Exploración & $\begin{array}{l}\text { Evaluación } \\
\text { y desarrollo }\end{array}$ & $\begin{array}{l}\text { Desarrollo y } \\
\text { producción }\end{array}$ & $\begin{array}{l}\text { Transporte y } \\
\text { almacenamiento }\end{array}$ & $\begin{array}{l}\text { Refinación y } \\
\text { petroquímicas }\end{array}$ \\
\hline Extranjera & 10,4 & 10,6 & $30 \%$ & $76 \%$ & $76 \%$ & $38 \%$ & $33 \%$ \\
\hline Nacional & 7,0 & 7,7 & $23 \%$ & $68 \%$ & $62 \%$ & $32 \%$ & $24 \%$ \\
\hline Total & 8,5 & 9,1 & $26 \%$ & $71 \%$ & $68 \%$ & $35 \%$ & $28 \%$ \\
\hline
\end{tabular}

Fuentes: Directorio Campetrol y cálculo de los autores.

Estas estadísticas muestran diferencias importantes o características que hacen que las empresas entren de manera diferente en la cadena de valor, lo cual parece estar relacionado con los retos tecnológicos que allí se presentan. Existen retos significativos en la etapa de exploración, refinación y petroquímicos. Cuando se toman en cuenta las diferencias en el capital, se observa que las empresas extranjeras buscan participar más activamente en todas las fases de la cadena, dado que el porcentaje de empresas con capital extranjero que ofrecen una amplia gama de servicios es significativamente más alto que el de empresas con capital nacional. Se puede pensar que las empresas extranjeras en promedio tienen más años de experiencia, son más amplias y tratan de diversificarse más a lo largo de la cadena de valor. Es importante notar las principales diferencias en desarrollo y producción y refinación entre empresas nacionales y extranjeras, donde estas últimas participan de manera más significativa en alguno de estos servicios.

Es esencial analizar estas estadísticas por la experiencia de la empresa y entender mejor en cuáles áreas están entrando empresas de menor experiencia (como una proxy de si son empresas nuevas), lo cual puede arrojar luz sobre el dinamismo reciente del sector. El cuadro 9 plantea las mismas estadísticas descriptivas por dos grupos de empresas: empresas jóvenes y empresas consolidadas. Las empresas jóvenes son aquellas que cuentan con 10 años de experiencia o menos en la provisión de servicios de hidrocarburos. En Colombia, 41 empresas cumplen con este criterio. Las empresas consolidadas son aquellas con experiencia superior a 10 años, y existen 118 empresas en esta categoría. El objetivo es entender si la entrada de empresas jóvenes está discriminada por tipo o fase en la cadena de valor del sector servicios. Las empresas jóvenes son menos diversificadas que las empresas consolidadas; es decir, ofrecen menos servicios y además son más homogéneas entre ellas. También es importante observar que las empresas jóvenes participan en menor medida en la fase de exploración, transporte y almacenamiento y en la refinación y petroquímicos, con valores de $20 \%$ o menos de todas las empresas jóvenes que ofrecen servicios. Por el contrario, estas firmas se concentran significativamente en la oferta de servicios en la fase de evaluación y desarrollo, con un valor cercano al $80 \%$. En desarrollo y producción también ofrecen servicios cerca del $66 \%$. 
Cuadro 9. Participación de las empresas por experiencia en la cadena de valor

\begin{tabular}{|c|c|c|c|c|c|c|c|}
\hline \multirow[b]{2}{*}{ Experiencia } & \multirow{2}{*}{$\begin{array}{l}\text { Promedio } \\
\text { servicios } \\
\text { ofrecidos }\end{array}$} & \multirow{2}{*}{$\begin{array}{l}\text { Variación } \\
\text { (desviación } \\
\text { estándar) }\end{array}$} & \multicolumn{5}{|c|}{$\begin{array}{l}\text { Porcentaje de empresas que ofrecen servicios en cada } \\
\text { fase de la cadena de valor }\end{array}$} \\
\hline & & & Exploración & $\begin{array}{l}\text { Evaluación } \\
\text { y desarrollo }\end{array}$ & $\begin{array}{l}\text { Desarrollo y } \\
\text { producción }\end{array}$ & $\begin{array}{l}\text { Transporte y } \\
\text { almacenamiento }\end{array}$ & $\begin{array}{l}\text { Refinación y } \\
\text { petroquímicas }\end{array}$ \\
\hline Jóvenes 10 años o menos & 12,2 & 12,4 & $20 \%$ & $80 \%$ & $66 \%$ & $17 \%$ & $20 \%$ \\
\hline Consolidadas (más de 10 años) & 16,2 & 16,3 & $29 \%$ & $69 \%$ & $69 \%$ & $41 \%$ & $31 \%$ \\
\hline Total & 8,5 & 9,1 & $26 \%$ & $71 \%$ & $68 \%$ & $35 \%$ & $28 \%$ \\
\hline
\end{tabular}

Fuentes: Directorio Campetrol y cálculo de los autores.

Las estadísticas descriptivas anteriores mostraron un panorama diferenciado por tipo de capital y experiencia. Las empresas extranjeras, en promedio, tienen más años de experiencia, son más grandes y tratan de diversificarse a lo largo de la cadena de valor. Por el contrario, las empresas nacionales son de existencia más reciente y buscan concentrarse en algunos servicios, en particular de evaluación y desarrollo. Con el objetivo de entender mejor esta tendencia se realizó un análisis más detallado de la participación de estas empresas por experiencia y tipo de capital para las tres etapas de la cadena de valor.

En la fase de exploración, el $26 \%$ de las 159 empresas del sector ofrecen por lo menos un servicio. En total, 42 empresas participan en esta fase, de las cuales 21 empresas tienen capital de origen nacional y 34 están consolidadas. El gráfico 9 presenta las estadísticas para cada una de las líneas de servicios de la fase de exploración, en la cual existe una participación significativa de empresas consolidadas y de capital extranjero. En primer lugar, debe recordarse que existen 9 líneas de servicios identificados en esta etapa de la cadena de valor; de estas, las líneas con mayor participación son perforación estratigráfica, construcción y mantenimiento de facilidades onshore y offshore y procesamiento de datos. Las de menor participación son gravimetría y magnetometría. De las 42 empresas identificadas en esta fase, las de capital nacional ofrecen servicios en mayor porcentaje en perforación estratégica, construcción y mantenimiento de facilidades (onshore), procesamiento de datos y topografía. En este último servicio, las empresas nacionales son más representativas que sus contrapartes extranjeras. En sismografía existe también un número mayor de firmas nacionales que ofrecen servicios. Cuando se observan estas mismas estadísticas según la experiencia de la empresa se nota que las empresas consolidadas que participan en exploración lo hacen de manera relativa en mayor medida, que sus contrapartes jóvenes, en todos los servicios excepto en topografía, en perforación y en construcción offshore y onshore. Por lo tanto, se puede resumir que la fase de exploración es dominada por empresas extranjeras consolidadas, que componen todo el mercado incluidos aquellos servicios de poca oferta como gravimetría, magnetometría y geoquímica. 


\section{Gráfico 9. Distribución por línea de servicios de las empresas según capital y experiencia en la fase de exploración (42 empresas identificadas)}
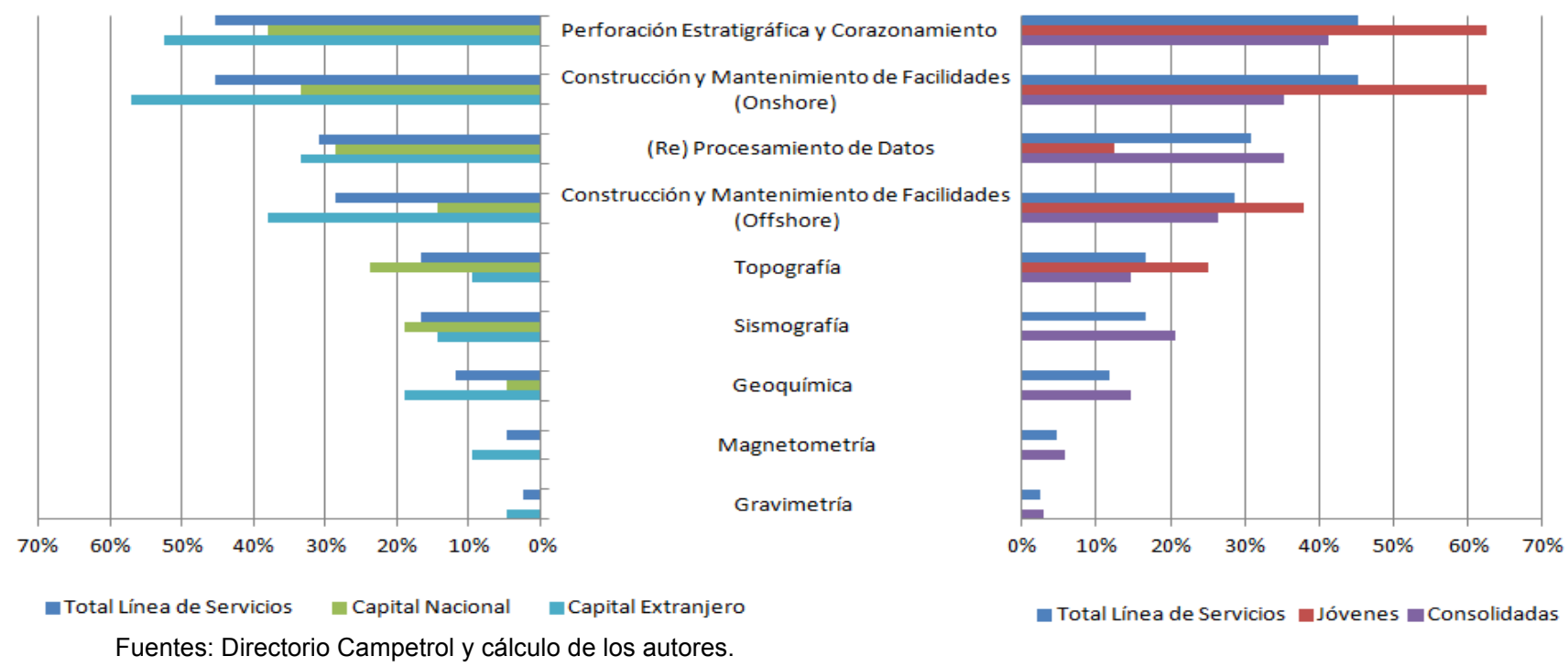

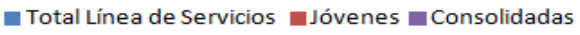

Las empresas que pertenecen a la fase de evaluación y desarrollo son 114, de las cuales 62 empresas tienen capital de origen nacional y 53 de origen extranjero. La gran mayoría de estas firmas (81) lleva en el mercado más de 10 años. Por su parte, la fase de evaluación está compuesta por 18 líneas de negocios, los cuales pertenecen a tres grupos: servicios generales (6 servicios), servicios de perforación ( 7 servicios) y servicios complementarios (5 servicios). El gráfico 10 expone la distribución de las empresas según capital y según experiencia para las líneas de servicios pertenecientes a cada grupo de la fase de evaluación y desarrollo. Se puede observar que la concentración de todas las firmas que pertenecen a los servicios generales es baja (panel superior del gráfico 10), donde la mayor cantidad de empresas son nacionales, las cuales al igual que las empresas jóvenes tienen una mayor concentración en obras civiles, pruebas de pozos y transporte de equipos (taladro y tubería). Por otra parte, dentro de todas las líneas de serivicio de evaluación y desarrollo, las empresas extranjeras y las empresas consolidadas se concentran mayormente en los servicios de obras civiles. Las firmas consolidadas se concentran en la línea de servicios profesionales especializados.

Los servicios del grupo de perforación (panel medio del gráfico 10) son dominados por las empresas extranjeras, que en todos los servicios tienen una mayor participación (tanto absoluta como relativa) que las empresas nacionales, concentrándose fuertemente en la prestación de servicios de perforación y en el de herramientas de perforación y completamiento. De igual forma, las empresas jóvenes tienen una mayor participación relativa con respecto a las consolidadas en la gran mayoría de los servicios de perforación, menos en los registros eléctricos y cañoneo y en los de fluidos de perforación, donde la participación es cercana, aunque un poco más fuerte por parte de las empresas consolidadas. La línea de registros eléctricos y cañoneo perteneciente al grupo de servicios de perforación es la que tiene un menor porcentaje de participación por parte de las empresas en general. 
Gráfico 10. Distribución por línea de servicios de las empresas según capital y experiencia en la fase de evaluación y desarrollo (114 empresas identificadas).

\section{Servicios generales}
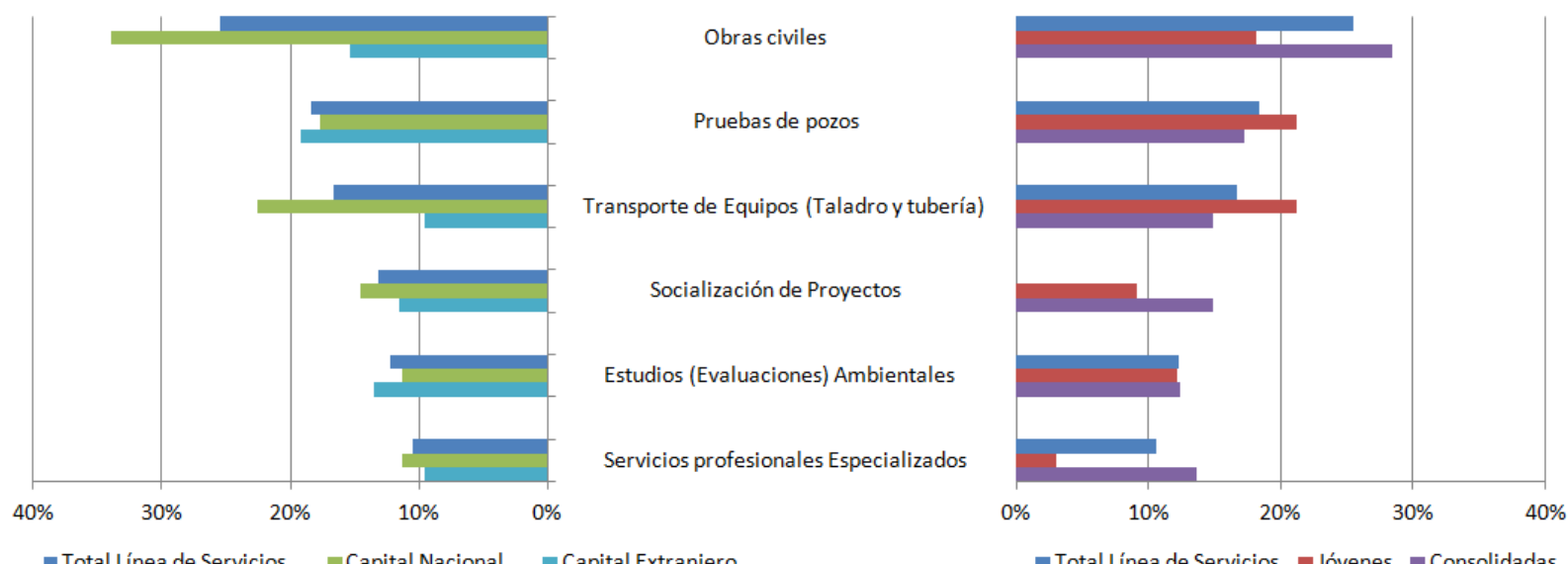

- Total Línea de Servicios $\quad$ Capital Nacional

\section{Servicios de perforación}

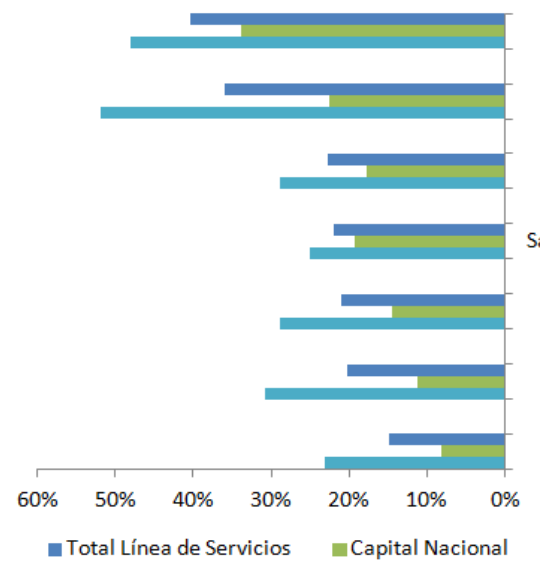

Herramientas Perforación y Completamiento

Servicios de Perforación

Fluidos de Perforación / tratamiento y Disposición

Sartas de revestimientos / producción válvulas

Cementación

Perforación Direccional

Registros Eléctricos y Cañoneo

n Total Línea de Servicios a Jóvenes n Consolidadas

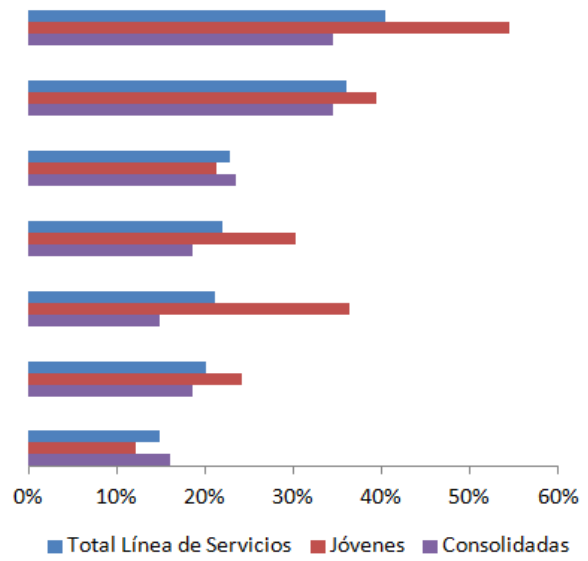

Servicios complementarios

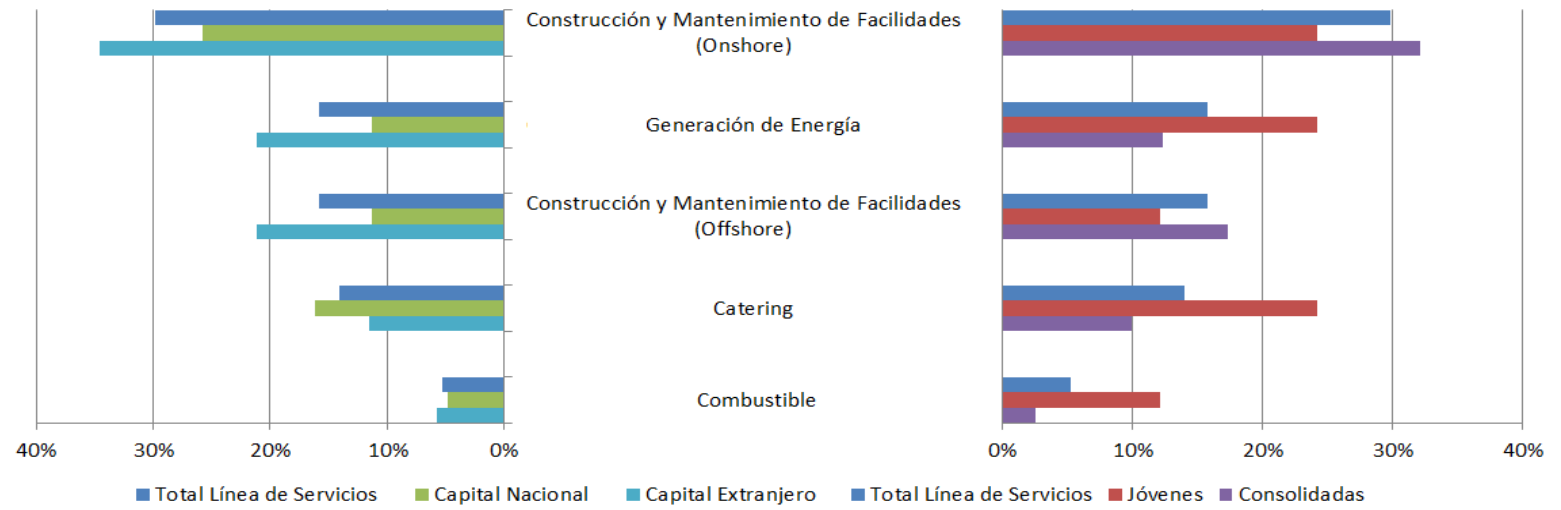

Fuentes: Directorio Campetrol y cálculo de los autores. 
En cuanto al tercer grupo de servicios que pertenece a la fase de evaluación y desarrollo, conocida como servicios complementarios, se evidencia una mayor participación de empresas extranjeras y consolidadas en los servicios de construcción y mantenimiento onshore y offshore. Por el contrario, los servicios de catering son dominados por empresas nacionales, en su mayoría jóvenes.

En resumen, la participación de las empresas en los servicios de evaluación y desarrollo es variada, pero se evidencia concentración de empresas en la prestación de servicios generales y de exploración. En el grupo de servicios generales se encuentran concentradas las empresas nacionales, y las empresas extranjeras se encuentran concentradas en la prestación de todo tipo de servicios de perforación. Finalmente, en el grupo de servicios complementarios participan todos los tipos de empresas: nacionales, extranjeras, jóvenes y consolidadas, y solo se presenta concentración de empresas extranjeras y consolidadas en la construcción y mantenimiento de facilidades.

Ahora bien, de las 159 empresas analizadas, 108 prestan servicios pertenecientes a la fase de desarrollo y producción, dentro de las cuales 56 empresas son nacionales y 81 tienen una experiencia mayor a 10 años en el mercado. El gráfico 11 muestra la participación significativa de todo tipo de empresas en la prestación de servicios de construcción y mantenimiento de facilidades (onshore y offshore) aunque en términos relativos, dicha participación es más fuerte para empresas de capital extranjero y consolidado. Las empresas extranjeras dominan los servicios de workover (reacondicionamiento) y mantenimiento al igual que los de estimulación de pozos. Por otra parte, la participación de empresas jóvenes y consolidadas en términos relativos tiende a ser similar para la prestación de servicios de levantamiento artificial y de construcción de líneas de flujo, las cuales son las líneas de menor participación para todas las firmas en general.

Gráfico 11. Distribución por línea de servicios de las empresas según capital y experiencia en la fase de desarrollo y producción (108 empresas identificadas)
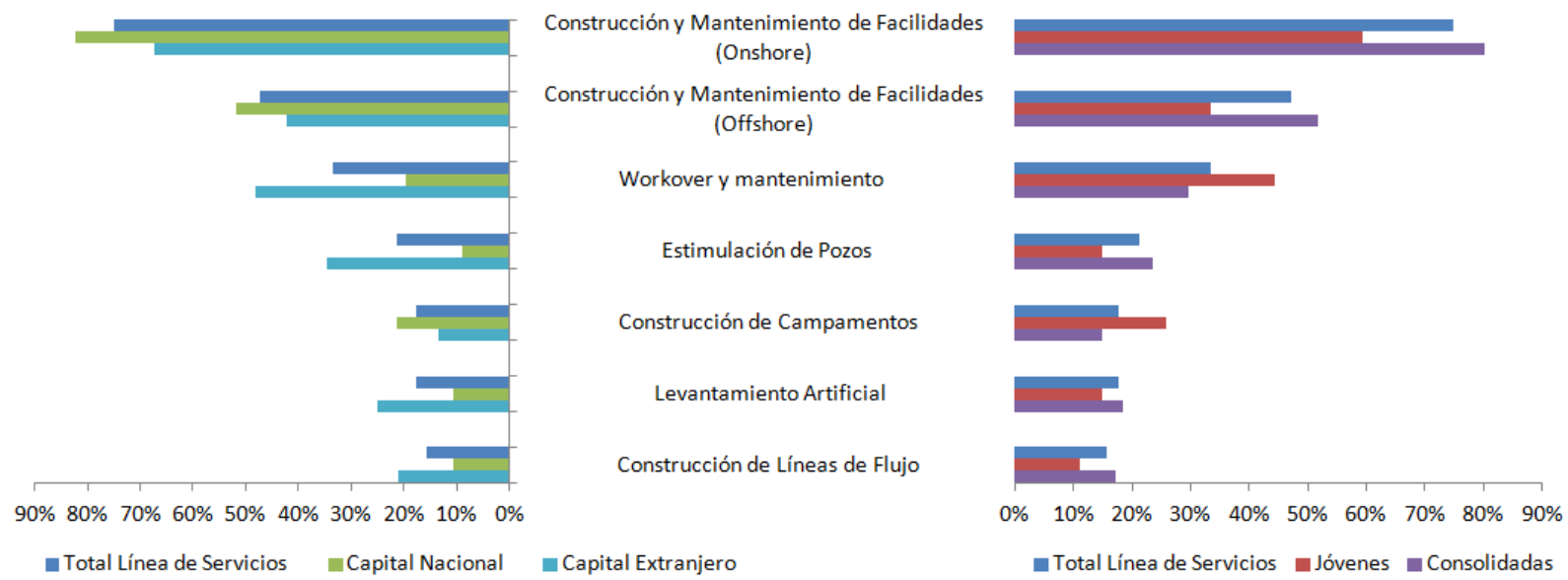

Fuentes: Directorio Campetrol y cálculo de los autores. 


\section{Caso de Ecopetrol: desarrollo de fases de la innovación y producción de bienes públicos.}

El caso de Ecopetrol, como empresa y hoy grupo empresarial, es importante de resaltar en este estudio por su trayectoria (path dependence). Esta empresa ha venido acumulando capacidades en los ámbitos organizacionales y empresariales, ha avanzado en el fortalecimiento de recursos humanos de muy alto nivel y en la generación de investigación y desarrollo tecnológico y se ha destacado por su innovación y transferencia de tecnología y por su modernización organizacional. Ecopetrol nació como empresa industrial y comercial del Estado en 1951, como producto de la reversión al Estado Colombiano de la Concesión de Mares. En 1961, asumió el manejo de la Refinería de Barrancabermeja y en 1974 compró la Refinería de Cartagena. En 1970, adoptó su primer estatuto orgánico y se ratificó como empresa comercial e industrial del Estado colombiano vinculada al Ministerio de Minas y Energía.

Ecopetrol es una sociedad mercantil dedicada a la industria del petróleo y áreas afines, y aunque su naturaleza es de empresa estatal, está regida por el derecho privado a excepción de normas específicas establecidas en la ley. En 1983 se descubrió el campo Caño Limón, de gran magnitud e importancia (1.100 millones de barriles), en colaboración con la petrolera Oxy. Este descubrimiento tuvo un impacto importante en la modernización de Ecopetrol, iniciando, como se indica en los anales de la empresa, "una nueva era" en su desarrollo. En 1986, Colombia nuevamente se convirtió en exportador de petróleo. En los años noventa, con el descubrimiento por parte de la British Petroleum Company del campo de Cusiana, primero, y luego del campo de Cupiagua, el país prolongó en el tiempo su condición de autosuficiencia de petróleo.

Desde sus inicios hasta 2003, Ecopetrol reunía las funciones de regulador, definidor de política petrolera y de operador, explorador con campos propios; sin embargo, mediante el Decreto 1760 del 26 de junio de 2003, el gobierno realizó la gran transformación de la empresa logrando que las compañías ya no tuvieran la obligación de asociarse con Ecopetrol para explorar y explotar los recursos de hidrocarburos y de gas. Mediante este decreto, se reemplazó la figura de contratos de conexión y se migró hacia contratos de asociación. Se estableció la responsabilidad de la política pública en el ámbito del Ministerio de Minas y Energía y la función de regulador fue asignada a la Agencia Nacional de Hidrocarburos (ANH), creada en el decreto para actuar como ente regulador de las áreas y los recursos de petróleo y gas, y responsable de las subastas y asignación de bloques para exploración y explotación. Además, la $\mathrm{ANH}$ es responsable por la administración de los recursos provenientes de las regalías.

Esta gran reforma modernizante liberó a Ecopetrol de sus funciones fundacionales que en tiempos modernos la volvían ineficiente y con gran deterioro de las capacidades adquiridas tanto en recursos humanos como en conocimiento, y la convirtió en una empresa capaz de competir en el mercado con otras empresas petroleras y de servicios, y hoy en día está entre las cinco empresas más grandes de Colombia. 
Durante todo este tiempo, desde su fundación, Ecopetrol —anteriormente llamada Empresa Colombiana de Petróleos- ha acumulado experiencia, desarrollos tecnológicos y de innovación, y dominio tecnológico internacional. En particular, en noviembre de 1985 se creó el Instituto Colombiano del Petróleo (ICP) como un centro de investigación, desarrollo e innovación. Forma parte de Ecopetrol para todo lo relacionado con la investigación, el desarrollo, la innovación, la ciencia y la tecnología. Cuenta con 20 laboratorios y 33 plantas piloto, con los que brinda soporte tecnológico a Ecopetrol y a proyectos conjuntos con asociados de la empresa. EI ICP se financia con recursos de Ecopetrol y obtiene recursos adicionales mediante participación en convocatorias de proyectos de investigación y de innovación en los ámbitos nacionales e internacionales, particularmente en el financiamiento de proyectos de investigación e incentivos que proporciona la entidad nacional de ciencia y tecnología, Colciencias. EI ICP trabaja en 8 áreas, que son: 1) reducción de riesgo exploratorio; 2) reducción de costos de desarrollo en el piedemonte; 3 ) optimización en campos de producción; 4) optimización de transporte de hidrocarburos; 5) optimización de refinación y petroquímica; 6) automatización y control de procesos; 7) optimización de la integridad de la infraestructura, y 8) desarrollo y aplicación de tecnologías limpias. EI ICP cuenta con recursos humanos calificados: 19 personas con doctorados, 63 con maestrías, 21 profesionales y 14 técnicos. Los desarrollos tecnológicos realizados en el ICP han generado en los últimos 8 años 144 nuevas solicitudes de patentes en Colombia y en el exterior, y tiene 56 patentes vigentes. En 2013 se le otorgaron a Ecopetrol 12 patentes, 7 en Colombia, 2 en México, 1 en China y 2 en Estados Unidos. El ICP-Ecopetrol cuenta con 178 productos tecnológicos, 125 registros de derechos de autor y 33 marcas comerciales. Entre 2011, 2012 y 2013 se han ejecutado en proyectos de investigación recursos por US\$179 millones.

En los anexos 1, 2, 3 y 4 se encuentra una descripción de las principales patentes otorgadas a ICP-Ecopetrol, de los productos tecnológicos más representativos, del software con registro y del ordenamiento de bases de datos y de marcas registradas. A nivel internacional se trabaja en red con las universidades de Calgary y Ontario de Canadá, Stanford, Oklahoma, Texas y Tulsa de Estados Unidos, e institutos como el Cenpes de Petrobras en Brasil. ICP y estas instituciones colaboran en proyectos conjuntos en sísmica $3 \mathrm{D}$, yacimientos fracturados, geomecánica, corrosión y materiales. Asimismo trabajan en red con investigadores de diferentes universidades del país.

\section{Marco regulatorio como dinamizador del mercado y su impacto sobre la cadena de valor, la innovación y los requisitos medioambientales}

\subsection{Consideraciones teóricas}

Los efectos de la regulación (económica, institucional y social) sobre los procesos de innovación en la economía pueden ser tanto positivos como negativos. Evidentemente, en el diseño de mecanismos regulatorios, uno de los criterios más significativos para la concepción de la regulación ha sido el de incrementar los efectos positivos de esta sobre los procesos de innovación tanto en el ámbito productivo como social. En este sentido, la pertinencia en el diseño de los mecanismos regulatorios hace indispensable reconocer la relación costo-beneficio de la regulación sobre la dinámica productiva, tecnológica y social, 
así como el rol del cambio tecnológico inducido por los procesos de innovación en la racionalidad y diseño de la regulación.

De esta forma, se plantea una relación bidireccional y dinámica entre regulación e innovación que ha generado un marcado interés en la literatura económica e institucional. En la literatura económica, la aproximación de crecimiento endógeno de Carlin y Soskice (2006), aplicada por Crafts (2006), en la cual la tasa de progreso tecnológico está determinada endógenamente, es el marco de análisis más reciente para medir los efectos de la regulación en el proceso de innovación. En este escenario, los efectos negativos de los costos de cumplimiento de la regulación deben compararse con los beneficios de los efectos dinámicos de la regulación en cuanto a los incentivos para acelerar el progreso tecnológico.

Por su parte, desde la perspectiva institucional, la OCDE (1997), en su esfuerzo por mejorar los efectos positivos de la regulación multidimensional sobre los procesos de innovación, recomendó en su momento que los procesos de reforma institucional y regulatoria de sus países miembros tuvieran en cuenta los siguientes criterios: i) estudiar en profundidad los vínculos entre regulación y tecnología, ii) promover la competencia, iii) diseñar esquemas regulatorios focalizados que eviten cargas innecesarias a los sujetos regulados, iv) emplear enfoques regulatorios descentralizados y compatibles con el avance tecnológico y v) facilitar la consolidación de estándares regulatorios en el ámbito internacional.

Así, la relación entre regulación, innovación y competitividad ha sido abordada durante las últimas décadas sin que se produzcan avances significativos para explicar el efecto de la regulación sobre la capacidad de innovación del sector productivo. Sin embargo, como lo plantean Blind et al. (2004), los diseñadores de política en materia de innovación sí han mostrado un marcado interés en emplear el marco regulatorio de la actividad productiva como un instrumento de política pública. En efecto, dadas las restricciones presupuestales de la actividad pública, destinar un monto creciente de recursos financieros para promover la innovación no es una alternativa factible en el mediano plazo. Es por esto que las autoridades de política, están cada vez más interesadas en el rol "facilitador" o "promotor" de la innovación que pueda tener el contexto regulatorio del sector productivo.

Más particularmente, en el caso de la cadena productiva de extracción de petróleo y gas, una innovación radical en el proceso de explotación de recursos no convencionales, tales como el gas de esquisto (shale gas). Esto ha generado un importante debate de política pública, en la medida en que se hace necesario redefinir el esquema de regulación y supervisión medioambiental sobre esta tecnología de forma tal que pueda ser aprovechada con una relación costo-beneficio óptima. ${ }^{6}$

De hecho, según Wang et al. (2014) Estados Unidos, líder en la adopción de las

\footnotetext{
6 Retos similares se observan en otros países latinoamericanos. En particular, en Argentina, más específicamente en Vaca Muerta, los expertos han resaltado como punto crítico el reto que enfrenta la política energética de ese país con respecto a la regulación en plazos para la explotación de pozos no convencionales, como un mecanismo de vital importancia para mover recursos de inversión hacia esa tipología de yacimientos.
} 
innovadoras técnicas de perforación horizontal y de inyección hidráulica para facilitar la explotación de recursos no convencionales, ha pasado de ser uno de los importadores más importantes de gas natural a ser autosuficiente en menos de una década. La producción interna de gas natural se multiplicó por 12 entre 2000 y 2010, lo cual facilitó que en 2012 el precio de este recurso alcanzara por primera vez su valor más bajo en 10 años de US $\$ 2$ por millón de BTU, comparado con el precio del petróleo de la variedad Brent de US\$80US\$100 por barril, equivalente a US\$14-US\$17 por millón de BTU. No obstante, este método de extracción ha sido sujeto de fuertes debates en el ámbito medioambiental y la salud humana por la incertidumbre que generan los impactos de las técnicas asociadas en el mediano y largo plazo.

Esta dicotomía hace trascendental reflexionar sobre el rol del contexto regulatorio en la industria extractiva de petróleo y gas, pues están en juego importantes recursos para la economía mundial, a partir de evidencias preliminares y no contundentes de los efectos medioambientales nocivos de la técnica de inyección hidráulica. De hecho, Werner et al. (2015) señalan que la evidencia disponible sobre los posibles efectos nocivos para el medio ambiente y la salud de los métodos no convencionales de extracción de gas natural carece de rigor metodológico. Sin embargo, a la fecha, no existe evidencia que descarte los efectos nocivos sobre la salud pública de las técnicas bajo análisis. En este escenario, el rol de la regulación para eliminar asimetrías de información e incentivar la investigación en este campo resulta trascendental para tomar una decisión social acertada sobre la viabilidad de esta metodología extractiva en el futuro.

Bajo el entendido de que la relación entre regulación e innovación es compleja, y dado que no se han identificado canales concretos a partir de la literatura empírica, la incertidumbre relativa sobre los impactos nocivos a la salud y el medio ambiente de las innovaciones más recientes en la extracción de petróleo y gas hace necesario compatibilizar dos elementos fundamentales, descritos anteriormente: i) el contexto regulatorio como herramienta de política para facilitar la innovación, y ii) la regulación como mecanismo para disminuir la incertidumbre e información asimétrica prevaleciente en cuanto a los impactos medioambientales y de salud pública de los nuevos métodos extractivos. $^{7}$

Más específicamente, es fundamental que la discusión sobre la pertinencia de la regulación en cuanto el despliegue de innovaciones en la industria de petróleo y gas no se centre en una visión categórica de aceptación o rechazo de esta industria, lo cual es el objeto del debate social del momento. Por el contrario, se debe enfatizar en el rol facilitador de innovaciones del contexto regulatorio, para promover escenarios en los que los procesos de investigación avancen significativamente en la definición de técnicas de identificación y mitigación de los impactos sociales y medioambientales.

\subsection{Políticas públicas, regulación, cadena de valor, innovación, requisitos medioambientales}

\footnotetext{
${ }^{7}$ Estos retos regulatorios pueden asociarse al surgimiento de líneas de servicios de empresas prestadoras de servicios en los temas medioambientales, lo cual puede ser de alto contenido local.
} 
En Colombia, el marco regulatorio, que se ha venido modernizando desde la perspectiva tanto del mercado como de bienes públicos, de la organización industrial e institucional se constituye en un elemento esencial de reglas de juego estables que crean condiciones favorables para la inversión extranjera y la participación de firmas nacionales en el sector petrolero. Asimismo, un elemento complementario e importante de las políticas públicas es que pueden favorecer o desfavorecer las condiciones para la permanencia estable y de largo plazo de la actividad del sector de hidrocarburos. Tanto el marco regulatorio como el marco del diseño de políticas e instrumentos de políticas públicas son factores que permiten una interrelación entre la innovación tecnológica y la sostenibilidad medioambiental, como se observa en el esquema 4.

El cambio tecnológico y los adelantos en la innovación por lo general son más acelerados que el marco regulatorio. Por ello, una buena regulación es la que permite de manera avanzada acompañar los cambios en el contexto y el entorno, y la que logra convertirse en eje articulador para resolver acertadamente y sin extremos arbitrajes y trade-offs entre los desarrollos tecnológicos y de innovación y los requisitos medioambientales. Lograr una buena práctica de políticas públicas en este ámbito es de extrema y fundamental importancia. Y también es de importancia esencial que las políticas públicas de tipo fiscal e impositivo, los fundamentos macroeconómicos, así como los estímulos y el suministro de bienes públicos de investigación y desarrollo, innovación y transferencia de tecnología sean estables y de mediano y largo plazo.

La anterior consideración es aún más relevante cuando la actividad pasa de ciclos de crecimiento y precios favorables, a ciclos de crisis de precios internacionales, como los que hoy prevalecen en el mercado petrolero mundial. La rentabilidad en épocas de expansión es favorable para las firmas, tanto nacionales como internacionales, lo cual cambia drásticamente en los ciclos de recesión de la actividad por la disminución de los precios. En este último contexto, la sobrevivencia de firmas pequeñas y medianas de base tecnológica con valor agregado de conocimiento es más difícil y requeriría formas organizacionales nuevas de asociatividad promovida y liderada por gremios y en concertación para poder permanecer en la actividad, dado que la estructura de costos cambia desfavorablemente para ellas. Por otra parte, la actividad petrolera en Colombia, si bien es importante y ha cambiado favorablemente a través del tiempo, aún sigue siendo de menor nivel que en otros países de la región o a nivel mundial, y esto puede llevar a que las firmas extranjeras mantengan sus compromisos pero no asuman nuevas búsquedas y migren hacia otros países con mucha mayor actividad y mejores condiciones.

Como se indicó inicialmente, la empresa estatal colombiana, que aún cuenta con cierto grado de integración de operación y servicios en la cadena de valor agregado, debería ser contracíclica frente a la situación actual de crisis de precios del crudo y debería en el mediano plazo mantener y aumentar, como objetivo de política pública, la exploración para poder lograr nuevos hallazgos de hidrocarburos, dados cinco elementos importantes que agregan dificultades: a) escasez de yacimientos convencionales, que van a hacer más difícil el tema de la exploración; b) estudios técnicos y exploración offshore que conlleva costos mucho mayores que la exploración tradicional de crudos livianos; c) menores posibilidades y probabilidades de recuperación primaria y mayores esfuerzos en 
recuperación secundaria y terciaria, que implica también mayores costos; d) exploración de crudos pesados, con tecnologías nuevas y de mayor costo, y con trade-off frente al tema medioambiental, y e) exploración y explotación de yacimientos no convencionales con el apoyo de tecnologías más costosas y con tensiones frente a la normatividad y la operatividad medioambiental.

Los cinco elementos mencionados no solo tienen validez para la empresa estatal sino que deben ser objeto de políticas públicas porque también afectan la rentabilidad actual de las empresas extranjeras situadas en el país. Como se mencionó, el gobierno ha tomado dos decisiones en esta vía en cuanto a normatividad e incentivos: incentivos fiscales y establecimiento de Zonas Francas Costa Afuera. El reto de la política pública por la mayor complejidad y dificultad enunciada con relación a la nueva realidad de búsqueda de hidrocarburos en condiciones diferentes a las tradicionales en el país es prever nuevas condiciones y necesidad de nuevas decisiones de política: contracíclica en períodos de crisis, manejo acertado de los fundamentos macroeconómicos, incentivos a la investigación, desarrollo, innovación y transferencia de tecnología; procesos de reglas de juego claros en los temas medioambientales, en cuanto a los tiempo y requisitos de las licencias medioambientales, que permitan compatibilizar el desarrollo sostenible y la innovación tecnológica en el nuevo contexto de condiciones de la exploración y explotación petrolera.

En 1994, a partir del descubrimiento del campo petrolífero de Cusiana, se estableció el Fondo de Estabilización Petrolera que buscaba garantizar un adecuado manejo de las divisas que generara Cusiana durante más de una década de bonanza. El objetivo era el de ahorrar en el exterior una parte de los recursos que ingresaran por la bonanza petrolera y simultáneamente evitar que el ingreso de dólares y su monetización se constituyeran en una nueva presión inflacionaria. Fue la época del gran debate de si Cusiana, uno de los mayores descubrimientos de petróleo del país, podría generar el fenómeno conocido como "enfermedad holandesa". La Ley 209 de 1995 creó el Fondo de Ahorro y Estabilización Petrolera (FAEP) como un sistema de manejo de cuentas en el exterior para un traslado temporal de las regalías y compensaciones con fines de ahorro fiscal y de estabilización petrolera. Mediante la Ley 633 de 2000 se autorizó la disposición de los recursos del Fondo de Ahorro y Estabilización Petrolera; esta ley estableció los criterios para el reparto y destinación de los mismos tanto a los departamentos como a los municipios en cuando a lo que les corresponde dentro del Fondo. Sin embargo, este Fondo se fue desmontando paulatinamente con el tiempo y es así como en la Ley 1530, Artículo 10, de 2012 se estableció, mediante el Decreto 1074 de 2012, que el Fondo de Ahorro y Estabilización Petrolera continuaría vigente hasta agotar los recursos incorporados en él y que las entidades partícipes de este Fondo podrían desahorrar anualmente en proporciones iguales y por el término de 8 años, hasta desahorrar el $100 \%$ de sus participaciones.

Fue el período del desahorro, que tendió a corregirse en parte con el Acto Legislativo 005 del 18 de julio de 2011, en el que se reformó el Sistema Nacional de Regalías. En la Ley de Regalías expedida se estable la existencia del Fondo de Ahorro y Estabilización Regional y que recibirá el 30\%, como un tope máximo anual, de los recursos 
provenientes de regalías, que en su mayor parte provienen del petróleo. Este Fondo de Ahorro, si bien depende de los ingresos petroleros, entre otros, puede servir de fondo de estabilización pero con la característica que hace parte de las regalías de regiones petroleras y no petroleras en las que se distribuyen los recursos para inversiones departamentales y municipales. Es de destacar que este Fondo no forma parte del presupuesto general de la nación sino de las regiones.

En síntesis, además de los retos anteriormente indicados, hay que resolver el falso dilema de Enfermedad Holandesa - Maldición del Petróleo (precios altos del petróleo que llevan a generar ingresos adicionales importantes en la economía) con cuestionamiento de las economías basadas en recursos naturales en momentos de crisis de precios, u otro tipo de crisis derivada de aspectos políticos o seguridad de abastecimiento. Una buena práctica de política macro en sus fundamentos es el reto de poder manejar los ciclos altos y los contraciclos de precios bajos, a través de fondos de estabilización, eficiencia en el uso de rentas estatales derivadas de los ingresos petroleros, combinación eficiente en términos de regulación de la demanda y equilibro fiscal (momento actual), a la vez que se sigue invirtiendo para lograr nuevos hallazgos que minimicen el riesgo de reservas petroleras muy bajas y a muy corto tiempo, como es el caso de Colombia, que tiene reservas para 6 años y medio. 


\section{Esquema 4}

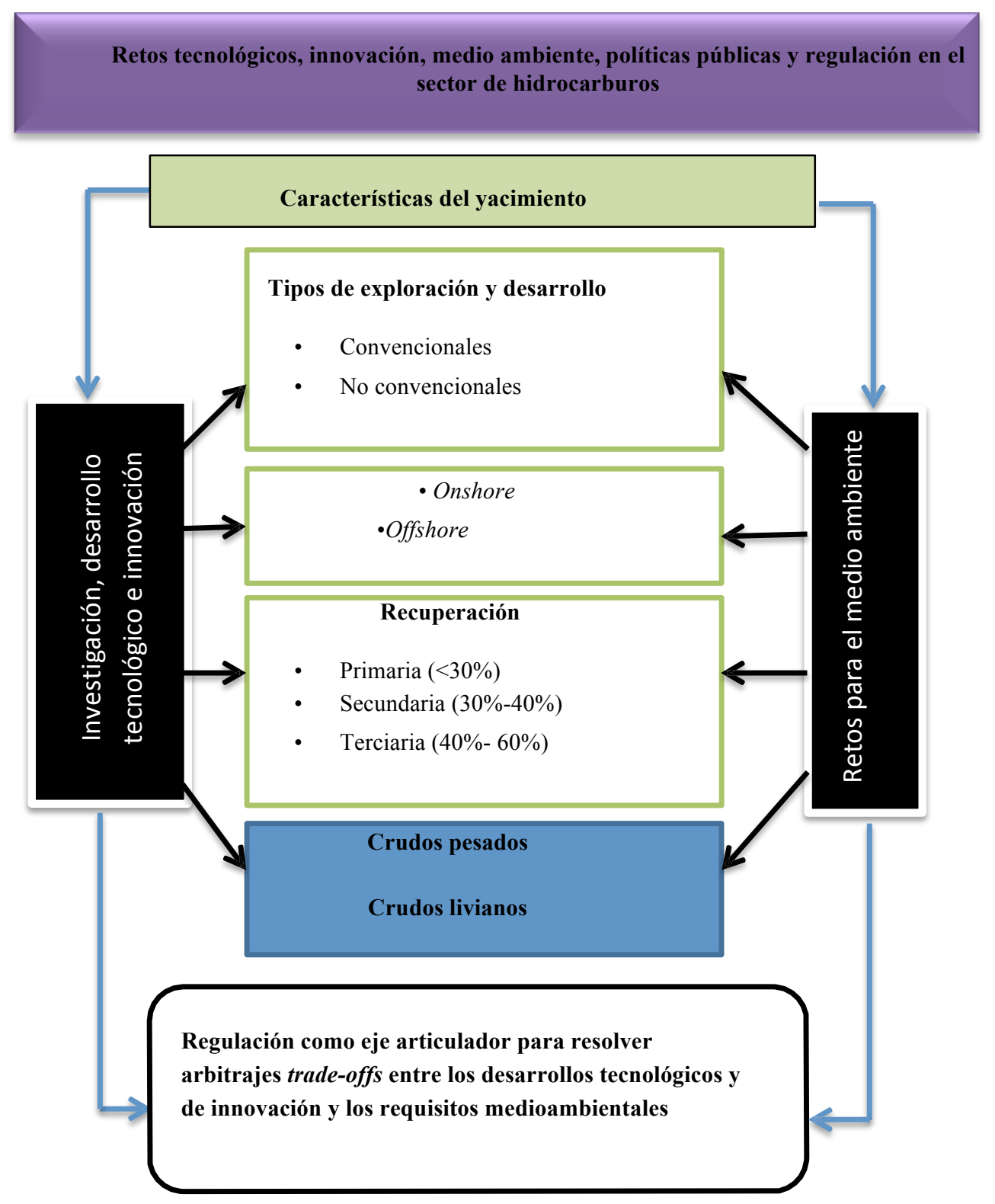




\section{Comentarios finales}

El sector de hidrocarburos en Colombia está compuesto por empresas con amplia experiencia en el sector, donde existen grandes multinacionales que fueron creadas varias décadas atrás y donde se puede observar la creación de un cuarto de las empresas existentes en los últimos 10 años. Además existe una mayor participación de empresas nacionales con respecto a las extranjeras, aunque la gran mayoría de empresas grandes del mercado son de origen extranjero, lo que hace que concentren la mayor parte de los ingresos operacionales del mercado, mientras que las nacionales tienden a ser medianas o pequeñas a excepción de pocas firmas que participan mayormente en construcciones.

Las empresas extranjeras en promedio tienen más años de experiencia, son más amplias y tratan de diversificarse más a lo largo de la cadena de valor y participan de manera más significativa en las fases de desarrollo y producción y refinación. Dentro de este grupo de empresas se identifica el liderazgo de Shlumberger Surenco S.A., que además de ser la empresa más grande del mercado, concentra la mayor parte de ingresos operacionales del mismo. Le siguen empresas como Weatherford Colombia Limited y Halliburton Latin America S.A., que también se encuentran dentro de las 5 empresas más grandes y con mayores niveles de ingresos operacionales.

Las empresas jóvenes son menos diversificadas que las empresas consolidadas, es decir ofrecen menos servicios, y además son más homogéneas entre ellas y participan en menor medida en la fase de exploración, transporte y almacenamiento y en la refinación y petroquímicos. Por su parte las empresas consolidadas participan de manera considerable y casi el doble en valores relativos en aquellos tipos de servicios que están menos ocupados por las empresas jóvenes. En cuanto a las fases que componen la cadena de valor, es claro que la fase de exploración es dominada por empresas extranjeras consolidadas, que componen todo el mercado para servicios como gravimetría, magnetometría y geoquímica. En cuanto a la fase de evaluación y desarrollo, en el grupo de servicios generales se encuentran concentradas las empresas nacionales, mientras que las empresas extranjeras se encuentran concentradas en la prestación de todo tipo de servicios de perforación; en cuanto al grupo de servicios complementarios participan todo tipo de empresas, nacionales, extranjeras, jóvenes y consolidadas, donde solo se presenta concentración de empresas extranjeras y consolidadas en la construcción y manejo de facilidades.

Finalmente no existe un dominio generalizado en esta fase por parte de algún tipo de empresas, aunque las empresas extranjeras consolidadas se concentran en la prestación de servicios de workover y mantenimiento y estimulación de pozos, mientras que las jóvenes y nacionales se concentran en la construcción de campamentos. 


\section{Bibliografía}

ACP. 2014. "YNC. Los Yacimientos no Convencionales y su importancia para Colombia”. Bogotá, Colombia. Mayo.

Benavides, J. (ed.). 2011. Ecopetrol, Energía limpia para el futuro. 60 Años. Bogotá, Colombia: Villegas Editores.

Blind, K., B. Bührlen, C. Kotz, K. Menrad y R. Walz. 2004. "New Products and Services: Analysis of Regulations Shaping New Markets". European Commission DG Enterprise. Luxemburgo.

Campetrol. 2014. "Directorio 2014". Bogotá, Colombia: Campetrol.

2012. "Colombia's OIL\&GAS industry. Perspective from the petroleum services sector". Calgary Economic Development - Matchmaking Session. 28 de mayo.

—_. 2010. "Offshore: Casos de referencia y Colombia". Boletín No. 7 (febrero).

Bogotá, Colombia: Campetrol.

Carlin, W., y D. Soskice. 2006. "Macroeconomics: Imperfections, Institutions \& Policies". Oxford, Reino Unido: Oxford University Press.

Crafts, N. 2006. "Regulation and productivity performance". Oxford Review of Economic Policy 22(2): 186-202.

Ecopetrol. 2014a. "Marco Estratégico". Vicepresidencia Corporativa de Estrategia y Crecimiento, Actualización. Bogotá, Colombia.

—. 2014b. "Los Yacimientos no Convencionales y su importancia para Colombia".

Presentación. Bogotá, Colombia. 6 de marzo.

Echeverry, J. C. 2015. "Perspectivas de Exploración en Colombia ante novedades en el mercado petrolero". EConcept, Análisis Económico Independiente, ANDI, Colombia Genera. Cartagena de Indias. 5 de febrero.

Felipe, C., et al. 2012. "Dinámica regional del sector de bienes y servicios petroleros en Colombia". Cuadernos de Fedesarrollo, No. 41. Bogotá, Colombia: Campetrol-Fedesarrollo.

Fernández, C., y L. Villar. 2014. "Bonanzas temporales de recursos: una perspectiva global". Fedesarrollo, Documento de Trabajo No. 60. Bogotá, Colombia: Fedesarrollo.

Forero, C., y E. Dávila. 2011. "La innovación y el aprendizaje tecnológico en la historia de Ecopetrol”. En: J. Benavides (ed.). Ecopetrol, Energía limpia para el futuro. 60 Años. Cap. 5, págs. 221 269. Bogotá, Colombia: Villegas Editores.

López, E., et al. 2013. "La economía petrolera en Colombia (Parte II). Relaciones intersectoriales e importancia en la economía nacional". Borradores de Economía, No. 748. Bogotá, Colombia: Banco de la República.

2012. "La economía petrolera en Colombia (Parte I). Marco legal - contractual, y principales eslabones de la cadena de producción (1920-2010)". Borradores de Economía, No. 692. Bogotá, Colombia: Banco de la República.

Martínez, O. A. 2012. "Política de proveedores del sector petrolero". Fedesarrollo. Bogotá, Colombia. Septiembre. 
OCDE. 1997. "The OECD Report on Regulatory Reform: Volume I: Sectorial Studies". París: OCDE.

Olivera, M., L. A. Zuleta, T. L. Aguilar y A. F. Osorio. 2011. "Impacto del Sector de Servicios Petroleros en La Economía Colombiana". Cuadernos de Fedesarrollo, No. 36. Bogotá, Colombia: Campetrol-Fedesarrollo.

Perry, G., y M. Olivera. 2009. "El impacto del petróleo y la minería en el desarrollo regional y local en Colombia". Documento de Trabajo 2009/6. Caracas, Venezuela: Corporación Andina de Fomento.

República de Colombia, Congreso de la República, Ley 1739 del 23 de diciembre de 2014, "Por medio de la Cual se Modifica el Estatuto Tributario, la Ley 1607 de 2012, se crean Mecanismos de Lucha contra la Evasión, y se Dictan Otras Disposiciones".

República de Colombia, Ministerio de Comercio, Industria y Turismo, Decreto Número 2682, de 23 de diciembre de 2014, "Por el cual se establecen condiciones y requisitos para la declaratoria de existencia de Zonas Francas Permanentes Costa Afuera".

República de Colombia, Ministerio de Minas y Energía, Resolución Número 90341 de 27 de marzo de 2014, "Por el cual se establecen requerimientos técnicos y procedimientos para la exploración y explotación de hidrocarburos en yacimientos no convencionales".

Rojas, N., y D., Forero. 2011. "Bonanza petrolera: ¿cómo aprovecharla?”. Concurso Germán Botero de los Ríos, 2010. Bogotá, Colombia: Fedesarrollo.

Serje, M., y C. Steiner. 2011. "La magia del petróleo: una aproximación a la historia social de Ecopetrol”. En: J. Benavides (ed.). Ecopetrol, Energía limpia para el futuro. 60 Años. Cap. 7 , págs. 319-360. Bogotá, Colombia: Villegas Editores.

Unidad de Planeación Minera Energética (UPME). 2013. "Cadena del Petróleo 2013". Bogotá Colombia: Ministerio de Minas y Energía. Diciembre.

__ 2012. "Escenario de oferta y demanda de hidrocarburos en Colombia". Bogotá, Colombia: Ministerio de Minas y Energía. Diciembre.

. 2011. "Boletín estadístico de minas y energía, 2007-2011". Bogotá, Colombia: Ministerio de Minas y Energía.

Wang, Q., X. Chen, A. N. Jha y H. Rogers. 2014. "Natural gas from shale formation - The evolution, evidences and challenges of shale gas revolution in United States". Renewable and Sustainable Energy Reviews 30: 1-28.

Werner, A., S. Vink, W. Kerrianne y P. Jagals. 2015. "Environmental health impacts of unconventional natural gas development: A review of the current strength of evidence". Science of the Total Environment, 505 (1 de febrero): 1127-1141. 


\section{Anexo 1}

\section{Principales patentes otorgadas de titularidad de Ecopetrol}

\begin{tabular}{|c|c|c|}
\hline TITULO DE LA PATENTE & $\begin{array}{c}\text { País de } \\
\text { radicación }\end{array}$ & Estado \\
\hline Proceso para la biodegradación natural estimulada de lodos aceitosos & Colombia & Vigente \\
\hline Herramienta desarenadora de pozos & Colombia & Vigente \\
\hline $\begin{array}{l}\text { Método para la detoxificación de soluciones que contienen níquel, } \\
\text { vanadio y bario, utilizando un biosorbente de origen fúngico }\end{array}$ & Colombia & Vigente \\
\hline $\begin{array}{l}\text { Proceso natural para la remoción de metales y desalación en sistemas } \\
\text { acuosos }\end{array}$ & Colombia & Vigente \\
\hline $\begin{array}{l}\text { Filtro biológico de flujo laminar para remoción de contaminantes de } \\
\text { efluentes industriales }\end{array}$ & Colombia & Vigente \\
\hline Method of produce low viscosity stable crude oil emulsion (eca) & USA & Vigente \\
\hline $\begin{array}{l}\text { On-line and/or batch process for production of fuel mixtures consisting } \\
\text { of coal/asphaltenes, fuel oil/heavy crude oil, surfactant and water } \\
\text { (ccta), and the obtained products }\end{array}$ & USA & Vigente \\
\hline Vanadium traps for catalyst for catalytic craking & USA & Vigente \\
\hline Interceptor de vanádio para catalizadores de ruptura catalítica & Brasil & Vigente \\
\hline Proceso para la biodegradación natural estimulada de lodos aceitosos & Ecuador & Vigente \\
\hline $\begin{array}{l}\text { Proceso semi-continuo para la biodegradación intensiva de lodos } \\
\text { aceitosos en sitio }\end{array}$ & Ecuador & Vigente \\
\hline $\begin{array}{l}\text { Proceso trifásico para la biodegradación intensiva de lodos aceitosos } \\
\text { en sitio }\end{array}$ & Ecuador & Vigente \\
\hline $\begin{array}{l}\text { Proceso de lavado emulsionante para la biodegradación intensiva de } \\
\text { lodos aceitosos }\end{array}$ & Ecuador & Vigente \\
\hline Herramienta magnética deshidratadora & Ecuador & Vigente \\
\hline $\begin{array}{l}\text { Proceso de lavado emulsionado trifásico para la recuperación de lodos } \\
\text { aceitosos }\end{array}$ & Venezuela & Vigente \\
\hline $\begin{array}{l}\text { Proceso trifásico para la biodegradación intensiva de lodos aceitosos } \\
\text { en sitio }\end{array}$ & Venezuela & Vigente \\
\hline Herramienta desarenadora de pozos & Venezuela & Vigente \\
\hline $\begin{array}{l}\text { Herramienta para el retiro seguro de válvulas instaladas en tuberías de } \\
\text { fluidos }\end{array}$ & Venezuela & Vigente \\
\hline $\begin{array}{l}\text { Equipo dosificador y procedimiento para el taponamiento de } \\
\text { derivaciones en ductos de transporte de fluidos basado en dicho }\end{array}$ & Nigeria & Vigente \\
\hline $\begin{array}{l}\text { Aditivos anti-gomas, antiensuciante y dispersantes de asfalto y } \\
\text { procedimiento para su obtención }\end{array}$ & Colombia & Vigente \\
\hline $\begin{array}{l}\text { Trampa de vanadio para el proceso de ruptura catalítica y su } \\
\text { preparación }\end{array}$ & Colombia & Vigente \\
\hline
\end{tabular}




\section{Anexo 2}

\section{Productos tecnológicos más representativos}

\begin{tabular}{|c|c|}
\hline PRODUCTO & DESCRIPCIÓN \\
\hline $\begin{array}{l}\text { Ecobiol: producto biotecnológico para el } \\
\text { tratamiento de residuos con } \\
\text { hidrocarburos. }\end{array}$ & $\begin{array}{l}\text { Células soportadas acompañadas de un activador } \\
\text { para aplicar en procesos de biorremediación de } \\
\text { hidrocarburos en aguas y suelos. }\end{array}$ \\
\hline $\begin{array}{l}\text { Modelo geomecánico de estabilidad de } \\
\text { pozos durante la perforación. Software: } \\
\text { Análisis Geomecánico de Estabilidad de } \\
\text { Pozos (AGE). }\end{array}$ & $\begin{array}{l}\text { Herramienta de diseño de pozo que permite } \\
\text { determinar las condiciones de las variables que } \\
\text { intervienen en un proyecto de perforación. }\end{array}$ \\
\hline Aditivos anticoque y antiensuciante. & $\begin{array}{l}\text { Aditivos antipolimerizantes y dispersantes } \\
\text { sintetizados para el control de la conversión en } \\
\text { plantas de viscorreducción y coquizadoras. }\end{array}$ \\
\hline $\begin{array}{l}\text { Método de limpieza interior de tanques } \\
\text { de almacenamiento de hidrocarburos. }\end{array}$ & $\begin{array}{l}\text { Metodología para limpieza de tanques de destilados } \\
\text { y de crudos livianos que consiste en: la } \\
\text { caracterización de los lodos a tratar, clasificación de } \\
\text { los lodos, definición de esquemas operacionales de } \\
\text { limpieza del tanque, manejo de productos hasta } \\
\text { disposición final y caracterización final de los } \\
\text { productos del tratamiento. }\end{array}$ \\
\hline $\begin{array}{l}\text { Zonación palinobiostratigráfica del } \\
\text { Paleoceno, Oligoceno, Mioceno- } \\
\text { Neógeno del norte de Suramérica. }\end{array}$ & $\begin{array}{l}\text { Permite tomar decisiones confiables y acertadas } \\
\text { operativamente sobre cambios de broca, puntos de } \\
\text { casing y dirección de desviación de los pozos, en el } \\
\text { momento de la exploración. }\end{array}$ \\
\hline Herramienta desarenadora de pozos. & $\begin{array}{l}\text { Diseñada para retirar arena, arcilla, lodo y otros } \\
\text { sedimentos que se depositan en el fondo del pozo y } \\
\text { en ocasiones obstruyen los intervalos productores o } \\
\text { inyectores, reduciendo sensiblemente la producción } \\
\text { o la eficiencia de la inyección de agua. }\end{array}$ \\
\hline $\begin{array}{l}\text { Asistencia computarizada para planes de } \\
\text { contingencia por derrames o escapes de } \\
\text { hidrocarburos (Acoplan). }\end{array}$ & $\begin{array}{l}\text { Software desarrollado para los encargados de } \\
\text { administrar y operar los planes de contingencia. Es } \\
\text { una herramienta de soporte para la toma de } \\
\text { decisiones al atender contingencias por derrames o } \\
\text { escapes de hidrocarburos. }\end{array}$ \\
\hline $\begin{array}{l}\text { Método para la detección, } \\
\text { caracterización y mapeo de anomalías } \\
\text { de hidrocarburos livianos en superficie } \\
\text { mediante técnicas cromatograficas y } \\
\text { estadísticas. }\end{array}$ & $\begin{array}{l}\text { Este método permite el mapeo de anomalías de } \\
\text { hidrocarburos livianos en superficie a partir de } \\
\text { muestras de suelo (onshore ) o muestras de } \\
\text { sedimentos (offshore). Las ventajas del método } \\
\text { incluyen su bajo costo y alta impacto en áreas donde } \\
\text { existe poca información geológica o ecológicamente } \\
\text { sensibles en donde se requiere un menor impacto } \\
\text { medioambiental y una mejor relación costo beneficio. }\end{array}$ \\
\hline $\begin{array}{l}\text { Metodología de integridad de mecánica } \\
\text { de pozos y su modelo de evaluación de } \\
\text { riesgo (SMIP 1.0) }\end{array}$ & $\begin{array}{l}\text { Herramienta para la valoración del riesgo de pozos } \\
\text { en producción basados en el cálculo de probabilidad } \\
\text { de falla y valoración de la consecuencia. }\end{array}$ \\
\hline $\begin{array}{l}\text { Metodología experimental para la } \\
\text { evaluación, selección y optimización de }\end{array}$ & $\begin{array}{l}\text { La metodología planteada sirve en la evaluación, } \\
\text { selección y optimización por medio de diferentes }\end{array}$ \\
\hline
\end{tabular}




\begin{tabular}{|l|l|}
\hline \multicolumn{1}{|c|}{ PRODUCTO } & \multicolumn{1}{c|}{ DESCRIPCIÓN } \\
\hline $\begin{array}{l}\text { fluidos de fractura para el incremento de } \\
\text { la producción en campos. }\end{array}$ & $\begin{array}{l}\text { pruebas de laboratorio, del fluido de fractura } \\
\text { apropiado para los trabajos de fracturamiento que se } \\
\text { aplican en los campos de petróleo. }\end{array}$ \\
\hline $\begin{array}{l}\text { Material compuesto orgánico (MCO) para } \\
\text { refuerzo de tuberías de conducción de } \\
\text { fluidos. }\end{array}$ & $\begin{array}{l}\text { Mezcla de una resina y una fibra orgánica. La fibra } \\
\text { se utiliza para dar sostenibilidad al sistema y } \\
\text { aumentar la resistencia general. Se emplea, según } \\
\text { su contextura, como aislante térmico o eléctrico y de } \\
\text { sustancias corrosivas en facilidades y líneas de } \\
\text { conducción de hidrocarburos. }\end{array}$ \\
\hline $\begin{array}{l}\text { Método de correlación crudo-roca y } \\
\text { crudo-crudo para crudos severamente } \\
\text { biodegradados. }\end{array}$ & $\begin{array}{l}\text { Método de correlación crudo-roca y crudo-crudo; } \\
\text { para crudos severamente biodegradados se basa en } \\
\text { la caracterización de biomarcadores ocluidos en la } \\
\text { malla de asfaltenos. }\end{array}$ \\
\hline $\begin{array}{l}\text { Determinación de biomarcadores } \\
\text { diamantoides en crudo. }\end{array}$ & $\begin{array}{l}\text { El producto "Metodología para la determinación de } \\
\text { biomarcadores diamantoides en crudos" consta de } \\
\text { las siguientes componentes: método de preparación } \\
\text { de la muestra, procedimiento técnico de ensayo, } \\
\text { preparación de muestra para análisis de } \\
\text { biomarcadores diamantoides, método } \\
\text { cromatográfico de análisis y procedimiento técnico } \\
\text { de ensayo biomarcadores diamantoides. }\end{array}$ \\
\hline
\end{tabular}




\section{Anexo 3}

\section{Software con registro de autor y bases de datos diseñadas}

\begin{tabular}{|l|l|r|}
\hline \multicolumn{1}{|c|}{ TíTULO DE LA OBRA } & Área tecnológica & $\begin{array}{c}\text { Número } \\
\text { del } \\
\text { registro }\end{array}$ \\
\hline $\begin{array}{l}\text { Sistema de información de planes de contingencia para } \\
\text { instalaciones petroleras (ACOPLAN) }\end{array}$ & Medioambiental & $13-1-80$ \\
\hline Modelo UNIBON & Refinación & $13-13-217$ \\
\hline $\begin{array}{l}\text { EcoElas2D V-2,0 - Software para la simulación de la } \\
\text { propagación de ondas elásticas en dos dimensiones utilizando el } \\
\text { método de diferencias finitas }\end{array}$ & Exploración & $13-14-326$ \\
\hline Modelo de simulación de la Planta DEMEX & Refinación & $13-15-447$ \\
\hline Modelo UNIBON 4.0 & Refinación & $13-16-3$ \\
\hline Sistema de Control de Pruebas de Laboratorio SCCPL & Gestión & $13-16-434$ \\
\hline Atlas de propiedades de rocas sello del norte de Colombia V-1 & Exploración & $13-18-131$ \\
\hline AGE V. 3.0 Análisis Geomecánico de Estabilidad & Producción & $13-18-176$ \\
\hline ASIA 2005 - Advanced System for Injection Analysis & Producción & $13-18-179$ \\
\hline Simulador de pruebas de presión numéricas (PPN V. 1.0) & Producción & \\
\hline $\begin{array}{l}\text { PVT+, Software para el manejo de fluidos de yacimiento de } \\
\text { petróleo y gas }\end{array}$ & Producción & $13-24-383$ \\
\hline $\begin{array}{l}\text { ECO-EMI: Herramienta para estimación de emisiones } \\
\text { atmosféricas en línea, en unidades cracking y plantas de azufre }\end{array}$ & Medioambiental & $13-26-400$ \\
\hline Software Silab WEB - Sistema para laboratorios & Transversal & $13-27-79$ \\
\hline FurSim - simulador de hornos de refinería & Refinación & $13-27-435$ \\
\hline Modelo de Hidrotratamiento de DIESEL & Refinación & $13-28-143$ \\
\hline $\begin{array}{l}\text { SVEAR - Software para el análisis económico y de riesgo e } \\
\text { incremento en proyectos de inyección de vapor }\end{array}$ & Producción & $13-28-401$ \\
\hline $\begin{array}{l}\text { EORS- Software para la realización de analogías entre campos } \\
\text { con procesos de recobro mejorado de hidrocarburos }\end{array}$ & Producción & $13-28-400$ \\
\hline $\begin{array}{l}\text { STEAM Software para cálculos asociados a procesos de } \\
\text { inyección de vapor }\end{array}$ & Producción & $13-28-399$ \\
\hline HEGA- Software para el gerenciamiento de alarmas & Transversal & $13-28-390$ \\
\hline
\end{tabular}




\section{Marcas registradas}

\begin{tabular}{|c|c|c|c|}
\hline MARCA & $\begin{array}{l}\text { Clasificación } \\
\text { Internacional }\end{array}$ & TIPOS & DESCRIPCIÓN DEL PRODUCTO \\
\hline Ccta & 1 y 4 & Nominativa & $\begin{array}{l}\text { Productos químicos destinados a la industria, } \\
\text { principalmente emulsión }\end{array}$ \\
\hline Acoplan & 9 & Mixta & $\begin{array}{l}\text { Soportes de registros magnéticos para } \\
\text { planes de contingencia por derrames o } \\
\text { escapes de hidrocarburos. }\end{array}$ \\
\hline Acoplan & 42 & Mixta & $\begin{array}{l}\text { Asistencia computarizada para planes de } \\
\text { contingencia por derrames o escapes de } \\
\text { hidrocarburos. }\end{array}$ \\
\hline Hdp & 7 & Nominativa & Máquina, herramienta desarenadora de \\
\hline Eca & 1 y 4 & Nominativa & $\begin{array}{l}\text { Emulsión carbón/tensoactivo/agua. } \\
\text { Principalmente productos químicos } \\
\text { destinados a la industria. }\end{array}$ \\
\hline Ecomaxbact & 1 & Nominativa & $\begin{array}{l}\text { Células soportadas acompañadas de un } \\
\text { activador para aplicar en procesos de } \\
\text { biorremediación de hidrocarburos en aguas }\end{array}$ \\
\hline Mco-strong & 42 & Nominativa & $\begin{array}{l}\text { Material que consiste en una mezcla de una } \\
\text { resina epóxica con un catalizador, de bajo } \\
\text { contenido de solventes y una fibra orgánica. } \\
\text { La fibra se utiliza para dar sostenibilidad al } \\
\text { sistema y aumentar la resistencia general. } \\
\text { Se emplea, según su contextura como } \\
\text { aislante térmico o eléctrico y de sustancias }\end{array}$ \\
\hline Ecoflot & 42 & Nominativa & \begin{tabular}{|l|} 
Proceso basado en la inyección de aire \\
atmosférico utilizando agua como fluido \\
motriz. En este proceso, el contacto aire- \\
agua se realiza mediante boquillas \\
inyectoras. El funcionamiento del sistema \\
consiste en recircular parte del agua por \\
tratar en la piscina. Se debe utilizar un \\
sistema de bombeo para enviar el fluido a un \\
vénturi abierto a la atmósfera. Al producirse \\
el cambio de velocidad dentro del vénturi, se \\
produce un vacío que induce aire hacia la \\
salida del mismo, mezclándolo con el agua \\
en forma de microburbujas, esta corriente \\
puede entonces ser distribuida por un \\
arreglo de tubería dentro de la piscina para \\
nrodurir la flntosión
\end{tabular} \\
\hline Ecokek plus & 1 & Nominativa & $\begin{array}{l}\text { Aditivo soluble en hidrocarburo, formulados } \\
\text { para reducir el ensuciamiento y formación de } \\
\text { coque en las superficies de los equipos } \\
\text { intercambiadores de calor, ocasionada por la } \\
\text { deposición de asfaltenos y residuos } \\
\text { carbonosos en los trenes de } \\
\text { precalentamiento de plantas de destilación } \\
\text { atmosférica, de vacío y viscoreductoras de } \\
\text { crudos. Los componentes activos de dicho } \\
\text { aditivo son obtenidos mediante } \\
\text { aminoalquilación y sulfonación de corrientes } \\
\text { de bajo valor. }\end{array}$ \\
\hline
\end{tabular}




\begin{tabular}{|l|l|l|l|}
\hline \multicolumn{1}{|c|}{ MARCA } & $\begin{array}{l}\text { Clasificación } \\
\text { internacional }\end{array}$ & TIPOS & DESCRIPCIÓN DEL PRODUCTO \\
\hline Biocetano & 4 y 42 & Nominativa & $\begin{array}{l}\text { Es un proceso para la obtención de } \\
\text { combustibles para el transporte por } \\
\text { hidrotratamiento de aceites de origen vegetal } \\
\text { utilizando tiempos de residencia bajos con lo } \\
\text { cual el tamaño del reactor se disminuye } \\
\text { notablemente con respecto a tamaños } \\
\text { convencionales lo cual hace que los costos } \\
\text { de inversiones se reduzcan a menos de la } \\
\text { mitad del costo de una planta convencional }\end{array}$ \\
\hline Eco-aleshia & 6 & Nominativa & $\begin{array}{l}\text { Sistema utilizado para separación de } \\
\text { emulsiones hidrocarburo agua en los } \\
\text { campos de producción usando únicamente } \\
\text { como energía de separación la fuerza de la } \\
\text { gravedad y los fenómenos naturales de } \\
\text { coagulación y coalescencia de fluidos } \\
\text { suspendidos. }\end{array}$ \\
\hline
\end{tabular}

